\title{
Full Paper \\ The role of diet and physical activity in breast, colorectal, and prostate cancer survivorship: a review of the literature
}

\author{
NJ Davies', L Batehup*,I and R Thomas ${ }^{2}$ \\ 'Self-Management Support Programme, National Cancer Survivorship Initiative, Macmillan Cancer Support, 89 Albert Embankment, London SEI 7UQ, \\ UK; ${ }^{2}$ Bedford Hospital and Addenbrooke's Hospital Cambridge University NHS Trusts, clo The Primrose Unit, Bedford Hospital, Bedford MK42 9DJ, UK
}

BACKGROUND: Evidence for the role of diet and physical activity in cancer incidence is well documented, but owing to increased cancer survivorship, an understanding of these lifestyle factors after a cancer diagnosis is of crucial importance. The purpose of this review was to update the literature in a review undertaken for the National Cancer Survivorship Initiative and to include observational studies that were not included in the WCRF survivorship systematic review.

METHODS: Evidence was initially gathered from pre-defined searches of the Cochrane Library Database and PubMed from March 2006 to February 20 10. After a comprehensive review regarding lifestyle and cancer, for the purpose of this article, any studies not related to diet and physical activity, prognostic outcomes, and breast, colorectal or prostate cancers were excluded. Another search of 20 I I literature was conducted to update the evidence.

RESULTS: A total of 43 records were included in this review. Evidence from observational studies suggests that a low-fat, high-fibre diet might be protective against cancer recurrence and progression. However, there is a paucity of RCTs substantiating this. There is more support for physical activity, with a dose response for better outcomes. When synthesized with findings from the World Cancer Research Fund review of RCTs investigating the effect of diet and physical activity interventions on cancer survival, evidence suggests that the mechanism of benefit from diet and physical activity pertains to body weight, with excess body weight being a risk factor, which is modifiable through lifestyle.

IMPLICATIONS: Cancer survivors would like to have a more active role in their health care and to know how to look after themselves after diagnosis, including what diet and lifestyle changes they should make. The challenge is in integrating lifestyle support into standardised models of aftercare.

British Journal of Cancer (20II) I 05, S52 -S73; doi:I0.1038/bjc.20II.423 www.bjcancer.com

(c) 20II Cancer Research UK

Keywords: diet; lifestyle; physical activity; weight

The role of a healthy diet and sufficient physical activity in cancer prevention have been well documented (Chan et al, 2005; Sonn et al, 2005), and it is widely accepted that a poor diet, lack of exercise, smoking and excessive alcohol consumption can increase an individual's risk of developing cancer. Increasing attention is now being given to the role of lifestyle in cancer survivorship.

There is a growing body of evidence for lifestyle interventions that aim to enhance healthy eating and weight management, and promote physical activity as having the potential to counter some of the adverse effects of cancer treatments, disease progression and other health outcomes (Pekmezi and Demark-Wahnefried, 2011). Besides the potential beneficial effect on recurrence, a healthy diet and regular physical activity may contribute to a reduced risk of comorbid conditions, such as other cancers, cardiovascular disease, diabetes, and so on (Jones and Demark-Wahnefried, 2006).

There have been a number of reviews and meta-analyses that have addressed issues of lifestyle factors and cancer prevention, the most comprehensive possibly being the 2007 report by the World Cancer Research Fund (WCRF), 'Food, Nutrition, Physical

*Correspondence: L Batehup; E-mail: LBatehup@macmillan.org.uk
Activity, and the Prevention of Cancer: A Global Perspective' (Bekkering et al, 2006). The recommendations from the expert panel are set out in Table 1. The expert panel recommendations on the evidence from the systematic review of RCTs on the effects of nutritional and physical activity interventions on cancer survival concluded that there is emerging evidence that some aspects of food, nutrition, or physical activity (all of which control body weight) may help prevent recurrence (of breast cancer). However, the evidence is not sufficiently developed to enable the panel to make judgements that apply specifically to cancer survivors and are distinct from those for people without cancer (Food, Nutrition, Physical Activity, and the Prevention of Cancer: A Global Perspective, Chapter 9, Cancer survivors, pp 342-347). More recent specific guidance on diet and physical activity for cancer survivors is becoming available. The British Association of Sport and Exercise Sciences has recently provided guidance on exercise and cancer survivorship (British Sport and Exercise Scientist, 24, Summer 2011), and the American College of Sports Medicine issued guidance on diet/physical activity for cancer survivors in 2010 (Schmitz et al, 2010). These recommendations for diet and physical activity are presented in Table 1, along with the UK recommendations for the general population (Department of Health, Macmillan Cancer Support, NHS Improvement, 2010). 

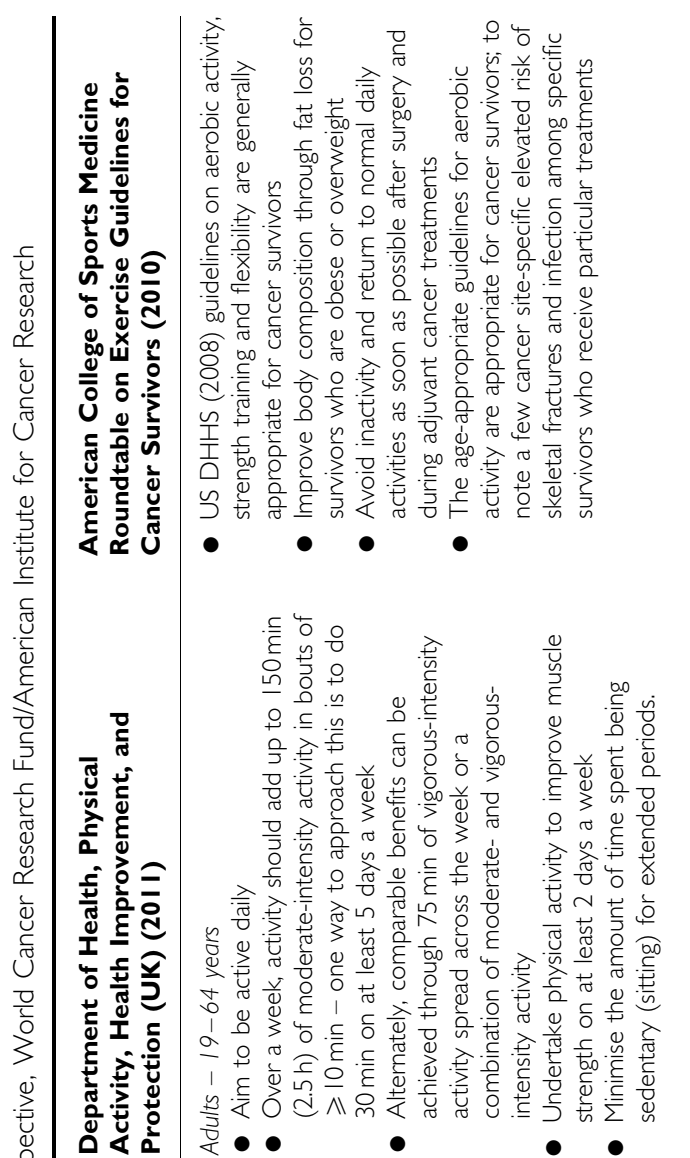

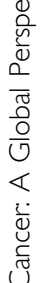


The purpose of this review was to update the literature review undertaken in 2010 for the National Cancer Survivorship Initiative (NCSI) (Davies et al, 2010), which covered evidence on lifestyle and cancer survivorship between 2006 and 2010, and to include observational studies that were excluded from the WRCF survivorship systematic review. A search for literature published between January and August 2011 was undertaken, which confined the search to include only literature for breast, prostate and colorectal cancer survivorship and lifestyle factors of diet and physical activity. The literature from the 2007-2010 review has been retained, which includes only breast, prostate and colorectal studies, and which is focused on diet and physical activity.

Survivorship, for the purpose of this review, was defined according to the definition within the NCSI Vision document (Department of Health, Macmillan Cancer Support, NHS Improvement, 2010). Survivorship 'encompasses those who are undergoing primary treatment, those who are in remission following treatment, those who are cured and those with active or advanced disease' (p 21).

\section{MATERIALS AND METHODS}

In 2010, as part of the NCSI, a selective review of the evidence for 'Advising Cancer Survivors about Lifestyle' (Davies et al, 2010) was conducted. The purpose of this review was to produce evidence that could support professionals in guiding and advising cancer survivors about the need and efficacy of making beneficial lifestyle changes after treatment for curative cancer, as well as to examine evidence published since the WCRF's 'A systematic review of RCTs investigating the effect of diet and physical activity interventions on cancer survival' (Bekkering et al, 2006). Records included within the review covered 2006-2010 and pertained to lifestyle-related factors (such as diet, physical activity, weight, smoking, alcohol consumption) for a number of cancer sites (such as breast, colorectal, lung, prostate cancer, and other tumour sites located as part of the search strategy). Outcomes of interest included prevention, survival, recurrence/progression, symptoms and treatment-related chronic conditions (such as fatigue, lymphoedema, osteoporosis, weight, physical fitness, quality of life, rehabilitation, behavioural change, health and well-being, cost-effectiveness).

For the purpose of this article, those studies related to outcomes other than recurrence and progression were removed, as were those studies related to lifestyle factors other than diet and physical activity. The cancer sites focused on include breast, colorectal and prostate cancers, which have received the greatest preponderance of work from the NCSI. To update the evidence, a further database search was conducted for 2011, the search terms being breast OR prostate OR colorectal AND cancer OR neoplasm AND diet ${ }^{\star}$ OR exercise OR physical activity OR weight OR lifestyle. Records were eligible if they met the following inclusion criteria: (1) lifestyle-related - diet or physical activity; (2) cancer sites: breast, colorectal or prostate; (3) trajectory - during primary cancer treatment or post-primary treatment; (4) outcomes of interest - survival, recurrence/progression; (5) adult population. Eligibility assessment was performed independently by three reviewers, with any disagreements between reviewers being resolved by consensus. Selection criteria were based on the PRISMA statement (Moher et al, 2009), which places systematic reviews, meta-analyses and RCTs as being 'gold standard' for evidence quality. Some studies before the initial search for 2006 records have been included, where the evidence offers further insights into those outcomes being examined.

Details of the studies included in this review (e.g., sample size, primary outcomes) are presented in Tables $2-5$, along with the adjusted hazard ratio (HR) or relative risk, $95 \%$ confidence interval (95\% CI), and significance levels. Diet, supplements and physical activity are presented separately for each of the three cancer sites being evaluated in this review.

A total of 43 records (Figure 1) were included in this review. In synthesising the evidence obtained from these records, site-specific findings are reported for breast, colorectal and prostate cancers. Where relevant, the evidence within the WCRF review is referred to, followed by additional evidence identified within the current review.

\section{RESULTS}

\section{Diet}

Recommendations for diet comprise guidance on limiting consumption of energy-dense foods with a high sugar or fat content (Table 1). The consumption of plant-based foods including fruit, vegetables and whole grains is recommended. Caution has also been raised against foods that are high in salt, including processed meats and mouldy cereals or pulses. The body of evidence from observational studies do increasingly indicate that obesity is a modifiable risk factor for both breast and colorectal cancer progression and survival (Patterson et al, 2010; Sinicrope et al, 2010).

Table 2 presents evidence obtained on diet for breast cancer from two large-scale multicentre RCTs - the Women's Intervention Nutrition Study (WINS) and the Women's Healthy Eating and Living (WHEL). These two large-scale studies (WINS, $n=2437$ and WHEL, $n=3088$ ) and the numerous subsequent secondary analyses are included in this review because of the significance of their dietary data and conflicting outcomes. Even after an indepth critique of the methods and interpretation of the WINS and WHEL outcomes, Patterson et al (2010), in their recent review of physical activity, diet and adiposity, and female breast cancer prognosis, concluded that data from these trials indicate that in a general population of breast cancer survivors, dietary interventions without weight loss or physical activity are not sufficient to improve breast cancer prognosis. Table 3 presents all other evidence obtained on diet for breast, colorectal, and prostate cancers.

Breast cancer Evidence for the role of dietary fat in breast cancer progression and survival was variable in the current review. A large prospective study $(n=90655)$ with an 8 -year follow-up found that dietary fat does increase the risk of recurrence or death in pre-menopausal women (Cho et al, 2003). These findings have been supported by the large multicentre prospective RCT, WINS, which found a protective benefit of a reduced-fat dietary intervention (Chlebowski et al, 2006). This protective benefit was more prominent in women diagnosed with hormone-receptornegative breast cancer $(n=2437)$. In this RCT, women were randomised to either a dietary intervention comprising a reduction in the percentage of calories from fat to $15 \%$ or a control group comprising standardised dietary guidelines. The hazard ratio (HR) of recurrence in the intervention group compared with the control group was 0.76 (95\% CI $=0.60-0.98 ; P=0.077)$. Furthermore, in 362 women with estrogen receptor (ER) and progesterone receptor (PR) disease, a significant overall survival (OS) benefit was seen in the intervention group $(7.5 \%$ vs $18.1 \%$, cumulative mortality) (Chlebowski et al, 2008). A subgroup analysis of 53 women revealed that elevated insulin concentrations may be influenced by dietary fat reduction $(P>0.05)$ (Khaodhiar et al, 2003). These findings point to the possibility that the mechanism of benefit obtained from a low-dietary-fat diet might be through its mediating effect on metabolic hormones such as insulin.

As low-fat diets are often accompanied by high intakes of fruit and vegetables, various components of a diet comprising high levels of fruit and vegetables have been investigated. Carotenoids 
Table 2 WINS and WHELs evidence

\begin{tabular}{ll}
\hline Author & Study design/intervention \\
\hline WINS & Interim analysis of a randomised, \\
Chlebowski & prospective, multicentre clinical trial \\
& (WINS) to test the effect of a dietary \\
intervention designed to reduce fat intake. & Randomisation was to: \\
& (I) Dietary intervention: reduce percentage \\
& of calories from fat to I5\%. The low-fat \\
& eating plan was initiated during 8 biweekly \\
& individual, in-person counselling sessions, \\
& each lasting I $\lambda$ h. Dietician 3 monthly, with \\
& optional monthly dietary group sessions. \\
& (2) Control group: one baseline dietician visit \\
& and contacts every 3 months thereafter. \\
& Written information provided on general \\
& dietary guidelines and counselling on \\
& nutritional adequacy for vitamin and \\
& mineral intake only
\end{tabular}

Chlebowski A protocol-mandated survival analysis et al (2008) update to the interim analysis of WINS

Dwyer et al (2008)

Khaodhiar et al Subgroup analysis of WINS participants (2003) (Chlebowski et al, 2006), examining relationships between dietary intake and insulin resistance
A subanalysis of participants in the WINS trial to determine whether differences existed in dietary intakes of flavonoids among WINS women who had been randomised to the very-low-fat diet after they modified their eating habits to achieve their goals. Comparisons were made between the intervention and control groups on intakes of total flavonoids and six flavonoid classes (isoflavones, flavones, flavanones, flavonols, flavan-3-ols and anthocyanins) using the US Department of Agriculture food flavonoid database and a flavonoid dietary supplement database on three 24-h dietary recalls at baseline and 12 months after randomisation
Breast cancer

patients

$(n=2437)$

$\begin{array}{lll}\text { Breast cancer } & \text { Mean }=60 & \text { Relapse-free } \\ \text { patients }(n=2437) & \text { months } & \text { survival; } \\ & \text { (5 years) } & \text { overall survival }\end{array}$

Follow-up Primary

period outcome

Results

A total of 277 relapse events have been reported in 96 of 975 (9.8\%) women in the dietary group and I8I of I 462 (I2.4\%) women in the control group. The HR of relapse events in the intervention group compared with the control group was $0.76(95 \% \mathrm{Cl}=0.60-0.98, P=0.077$ for stratified log rank and $P=0.034$ for adjusted Cox model analysis)

\section{7 years}

Overall survival

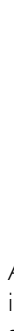

Although fewer deaths were seen in the intervention group, this was not statistically significant. In 362 women with ER and (progesterone receptor) PR disease, a significant overall survival benefit was seen in the intervention group ( 7.5 vs $18.1 \%$, cumulative mortality)

Randomly selected breast cancer patients $(n=550$; 218 from the dietary intervention and 332 from the control group)

53 women from 3 clinical sites

2 years after commencing intervention
Disease-free survival

After 12 months of intervention, with 39 participants lost to follow-up, flavonoid intakes remained similar in both groups ( $201 \pm 252$ s.d. $m g$ per day, $n=316$ in the usual diet group vs $235 \pm 425$ s.d. mg per day, $n=195$ in the very-low-fat group: $P=N S)$. In this random sample of WINS participants, neither total flavonoid intakes nor intakes of subclasses of flavonoids differed between those who had dramatically decreased their fat intakes and those who had not. Flavonoid intakes are therefore unlikely to account for WINS results

Of those women with initial insulin resistance, after I year, women in the intervention group saw their fasting insulin decrease by $18 \pm 34 \mu \mathrm{Uml}^{-1}$; in comparison, fasting insulin of women in the control group decreased by only | $3.8 \pm 47 \mu \cup \mathrm{ml}^{-1}$. Although not quite statistically significant, these results predict that elevated insulin concentrations may be influenced by dietary fat reduction

There were no additional health benefits

Breast cancer $(n=3088)$
After 7 years of Invasive intervention breast cancer incidence or recurrence; death from any cause of dramatically increasing intake of nutrient-rich plant-based foods, relative to the comparison group intervention: promoting a daily dietary intake of 5 vegetable servings, 16 oz of vegetable juice, 3 fruit servings, $30 \mathrm{~g}$ fibre and $15-20 \%$ of energy from fat. (2) Control group: received printed materials (but no counselling) promoting the five-a-day guidelines of daily intakes of 5 servings of fruit and vegetables, $>20 \mathrm{~g}$ of fibre and $<30 \%$ of energy from fat

Pierce 
Table 2 (Continued)

\begin{tabular}{|c|c|c|c|c|c|}
\hline Author & Study design/intervention & $\begin{array}{l}\text { Sample/ } \\
\text { inclusion }\end{array}$ & $\begin{array}{l}\text { Follow-up } \\
\text { period }\end{array}$ & $\begin{array}{l}\text { Primary } \\
\text { outcome }\end{array}$ & Results \\
\hline $\begin{array}{l}\text { Thomson et al } \\
\text { (2007) }\end{array}$ & $\begin{array}{l}\text { Subanalysis of a purposive sample of } \\
\text { participants in the WHEL RCT (see Gold } \\
\text { et al, } 2009 \text { in this table) }\end{array}$ & $\begin{array}{l}\text { Breast cancer } \\
\text { patients }(n=207)\end{array}$ & Not reported & $\begin{array}{l}\text { Oxidative } \\
\text { stress }\end{array}$ & $\begin{array}{l}\text { Dietary carotenoid levels were not } \\
\text { significantly associated with oxidative, stress } \\
\text { indicators, although dietary lycopene and } \\
\text { lutein/zeaxanthin were modestly associated } \\
\text { with } 8-O H d G \text { levels }(P=0.054 \text { and } 0.088 \text {, } \\
\text { respectively). Key findings include a } \\
\text { significant inverse association between total } \\
\text { plasma carotenoid concentrations and } \\
\text { oxidative stress as measured by urinary } \\
8-O H d G \text { and a moderately significant } \\
\text { inverse association with } 8 \text {-iso-PGF2 } \alpha \text {, a } \\
\text { protective association that was not shown } \\
\text { for dietary carotenoid intake }\end{array}$ \\
\hline $\begin{array}{l}\text { Gold et al } \\
(2009)\end{array}$ & $\begin{array}{l}\text { Secondary analysis of a purposive sample of } \\
\text { WHEL participants, to determine whether } \\
\text { a low-fat diet high in vegetables, fruit and } \\
\text { fibre affects prognosis in breast cancer } \\
\text { survivors with or without HFs after } \\
\text { treatment }\end{array}$ & $\begin{array}{l}2967 \text { women } \\
\text { whose baseline } \\
\text { HF severity report } \\
\text { in the previous } 4 \\
\text { weeks was available }\end{array}$ & $\begin{array}{l}7.3 \text { years into } \\
\text { the } \\
\text { intervention }\end{array}$ & $\begin{array}{l}\text { Additional } \\
\text { breast cancer } \\
\text { events and } \\
\text { death from } \\
\text { any cause }\end{array}$ & $\begin{array}{l}\text { HF-negative women in the intervention } \\
\text { had a } 31 \% \text { lower event rate than did } \\
\text { HF-negative women in the comparison } \\
\text { group over } 7.3 \text { years of follow-up; among } \\
\text { HF-negative post-menopausal women, } \\
\text { the intervention effect was even stronger, } \\
\text { with a } 47 \% \text { reduction in risk compared } \\
\text { with HF-negative women assigned to } \\
\text { the comparison group. Compared with } \\
\text { HF-negative women in the comparison } \\
\text { group, women with baseline HFs had a } \\
\text { lower risk of additional breast cancer } \\
\text { events, regardless of whether they were } \\
\text { randomly assigned to the dietary } \\
\text { intervention group or to the comparison } \\
\text { group }\end{array}$ \\
\hline $\begin{array}{l}\text { Caan et al } \\
(20 \mid 1)\end{array}$ & $\begin{array}{l}\text { Examination of data from the WHEL } \\
\text { study, to explore the effect of soy intake } \\
\text { on breast cancer prognosis. Isoflavone } \\
\text { intakes were measured after diagnosis by } \\
\text { using a food-frequency questionnaire. } \\
\text { Women self-reported new outcome } \\
\text { events semi-annually, which were then } \\
\text { verified by medical records and/or death } \\
\text { certificates }\end{array}$ & $\begin{array}{l}3088 \text { breast } \\
\text { cancer survivors, } \\
\text { diagnosed between } \\
1991 \text { and } 2000 \\
\text { with early-stage } \\
\text { breast cancer }\end{array}$ & $\begin{array}{l}\text { Median of } \\
7.3 \text { years }\end{array}$ & $\begin{array}{l}\text { Breast cancer- } \\
\text { related } \\
\text { mortality }\end{array}$ & $\begin{array}{l}\text { As isoflavone intake increased, risk of death } \\
\text { decreased ( } P \text { for trend }=0.02) \text {. Women } \\
\text { at the highest levels of isoflavone intake } \\
\text { ( }>16.3 \mathrm{mg} \text { isoflavones) had a non- } \\
\text { significant } 54 \% \text { reduction in risk of death }\end{array}$ \\
\hline
\end{tabular}

Abbreviations: $\mathrm{Cl}=$ confidence interval; $\mathrm{ER}=$ oestrogen receptor; $\mathrm{HF}=$ hot flush; $\mathrm{HR}=$ hazard ratio; $\mathrm{NS}=$ non-significant; $\mathrm{RCT}=$ randomised controlled study; WHEL $=$ Women's Healthy Eating and Living; WINS = Women's Intervention Nutrition Study.

have received particular attention, with past evidence suggesting that carotenoids do have a role in survival (Ingram, 1994). More recent prospective longitudinal RCTs have found this not to be the case, such as the WHEL RCT (Pierce et al, 2007). In the WHEL trial, women $(n=3088)$ were randomised to either an intensive telephone-counselling intervention promoting daily dietary intake of 5 vegetable servings, $16 \mathrm{oz}$ vegetable juice, 3 fruit servings, $30 \mathrm{~g}$ fibre and $15-20 \%$ of energy from fat, or a control group promoting the five-a-day guidelines of daily intakes of 5 servings of fruit and vegetables, $>20 \mathrm{~g}$ of fibre and $<30 \%$ of energy from fat. There were no additional health benefits of dramatically increasing intake of nutrient-rich plant-based foods relative to the control group. However, as pointed out by Patterson et al (2010), it is possible that the level of dietary change achieved in both the WINS and WHEL interventions was not sufficient to change cancer prognosis, or that the wrong dietary components were being examined.

When Gold et al (2009) conducted a secondary analysis of 2967 participants in the WHEL RCT, it was found that hot flush (HF)-negative women in the intervention had 31\% fewer events than did HF-negative women in the control group over 7.3 years of follow-up. Among HF-negative post-menopausal women, the intervention effect was even stronger, with a $47 \%$ reduction in risk compared with HF-negative women assigned to the comparison group. Compared with HF-negative women in the comparison group, women with baseline HFs had a lower risk of additional breast cancer events, regardless of whether they were randomly assigned to the dietary intervention group or to the comparison group. The poorer prognosis among HF-negative women and the protective effect of the WHEL intervention diet in this subgroup may be related to circulating oestrogen concentrations. In this secondary analysis of the WHEL study, a diet high in vegetables, fruit and fibre with reduced fat seemed to remove the excess risk of additional breast cancer events after treatment for early-stage breast cancer in women without HFs. This dietary effect was robustly observed across a series of sensitivity analyses. It was not modified by hormone receptor status or by the use of anti-oestrogen therapy and was not observed in participants who reported HFs. These results suggest that a major change in dietary pattern may be beneficial for some breast cancer survivors, although these findings need to be confirmed in a trial with the primary objective of determining the differential effect of the diet in breast cancer survivors with and without HFs. 


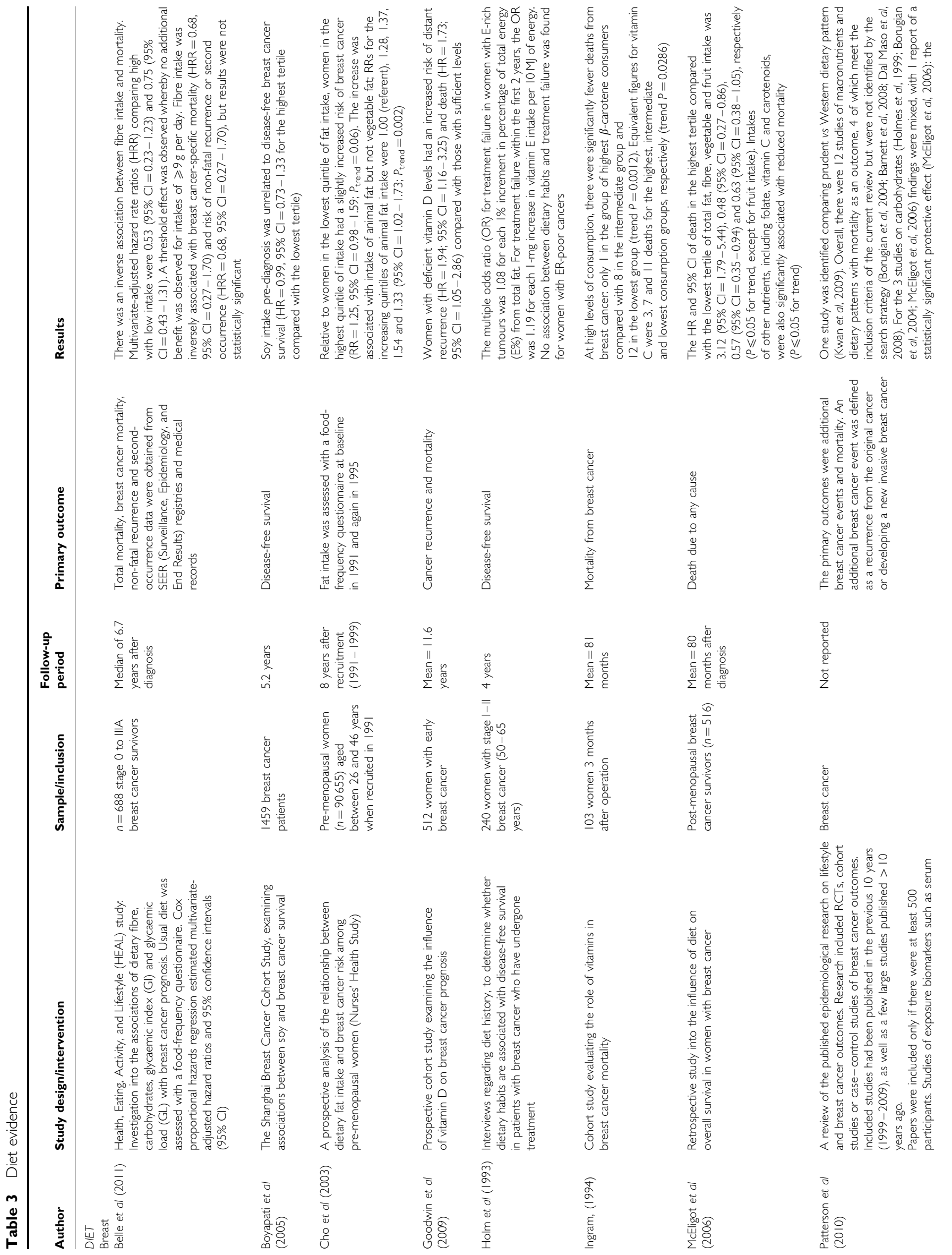




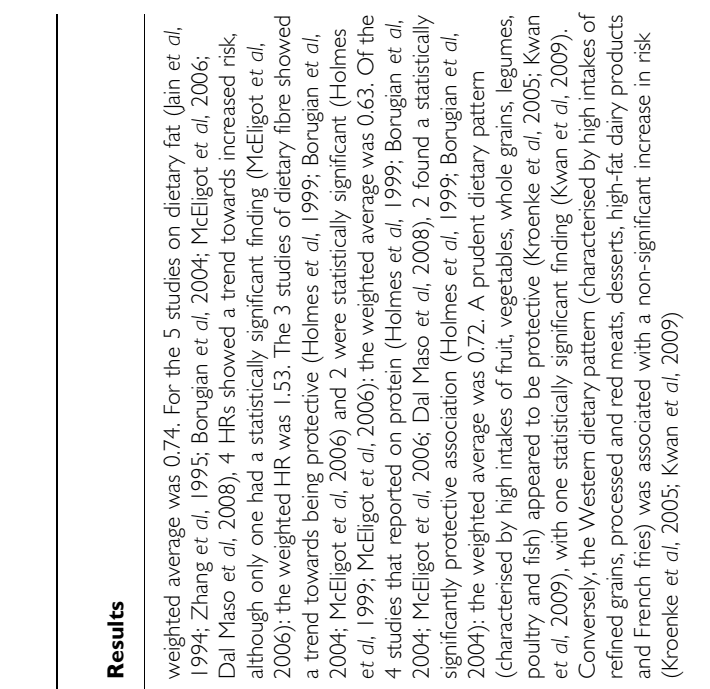

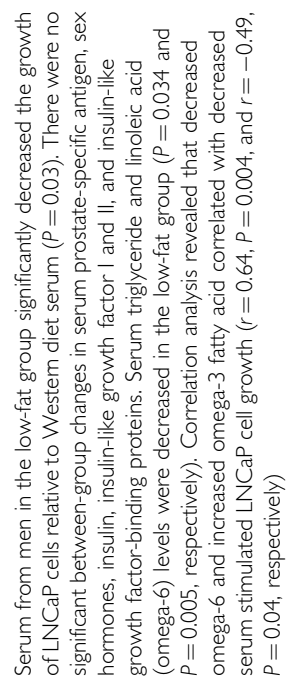

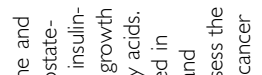

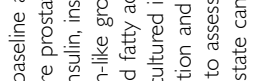

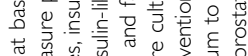

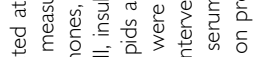

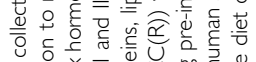

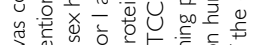

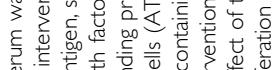

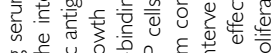

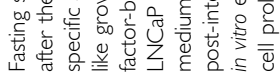

离

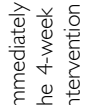

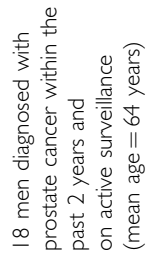

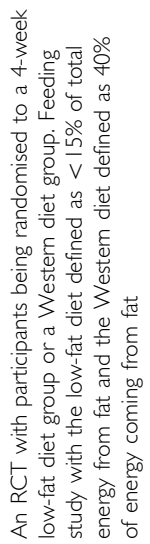

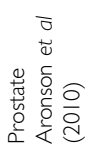



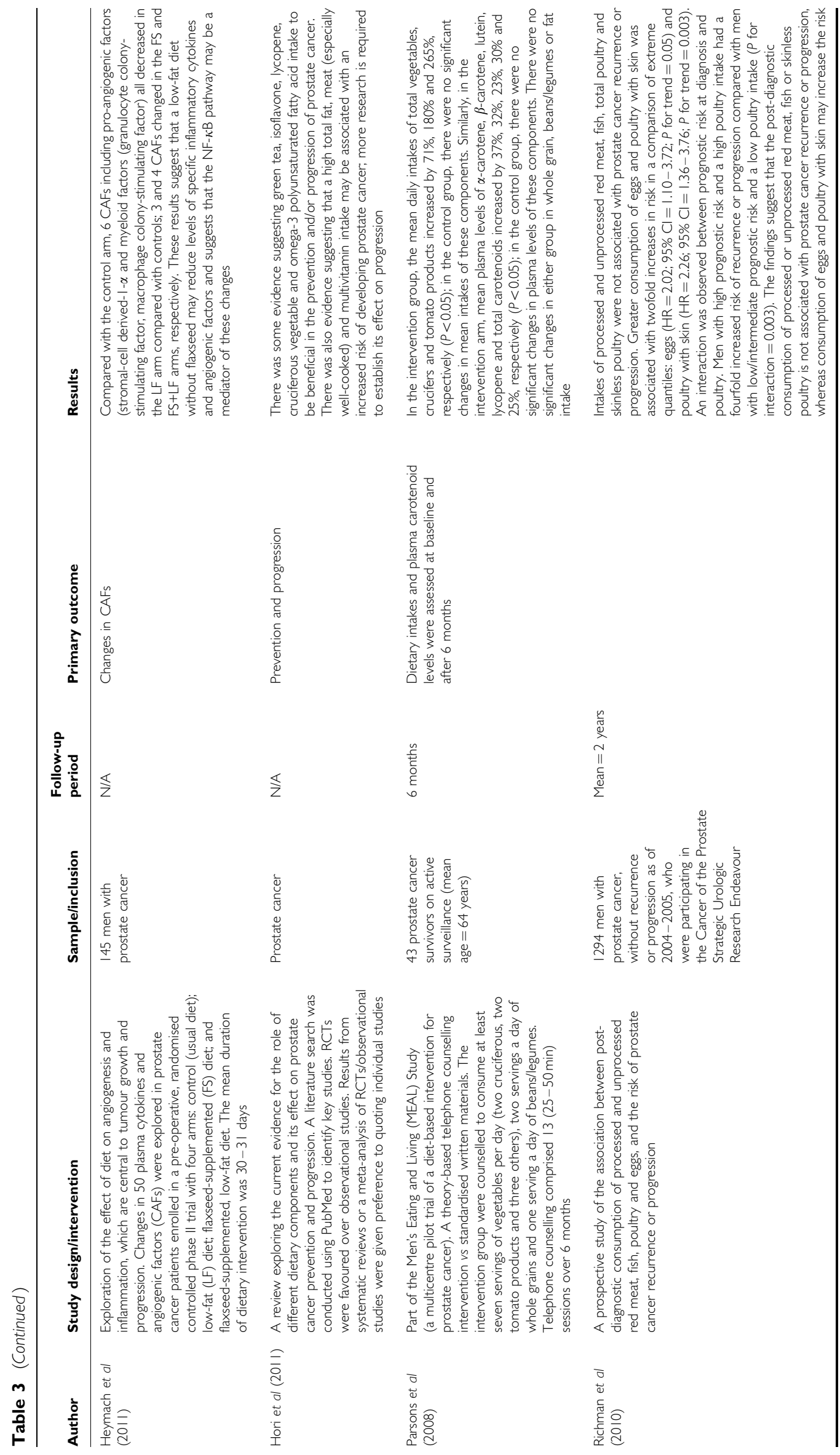

$\stackrel{\longleftarrow}{\Sigma}$

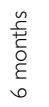

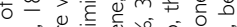

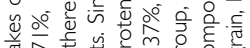

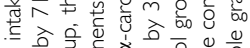

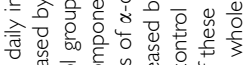

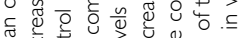
要.

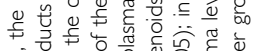

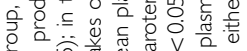

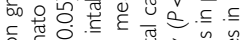

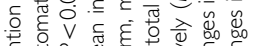

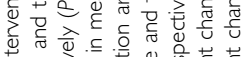

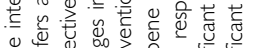

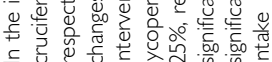

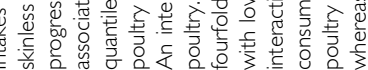
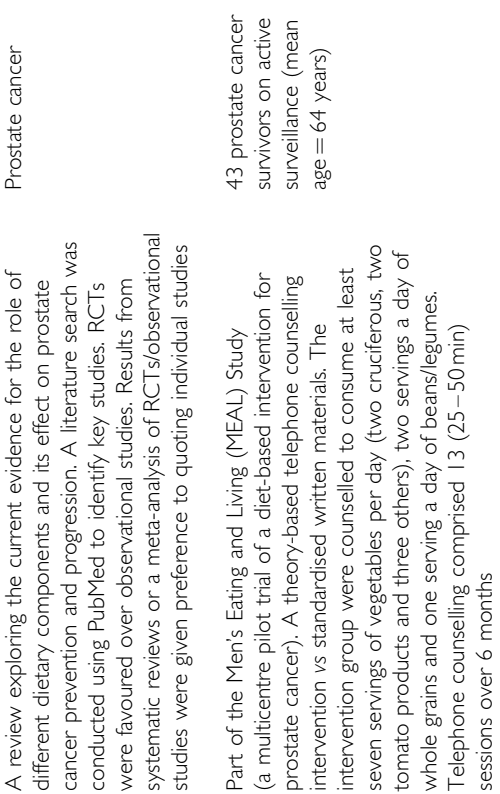

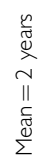

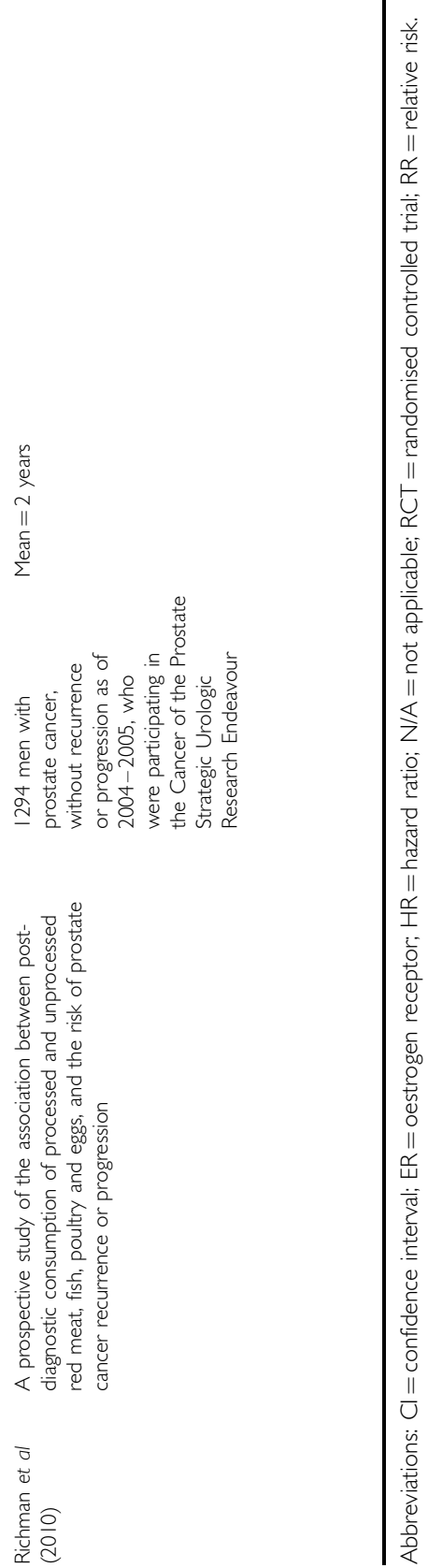




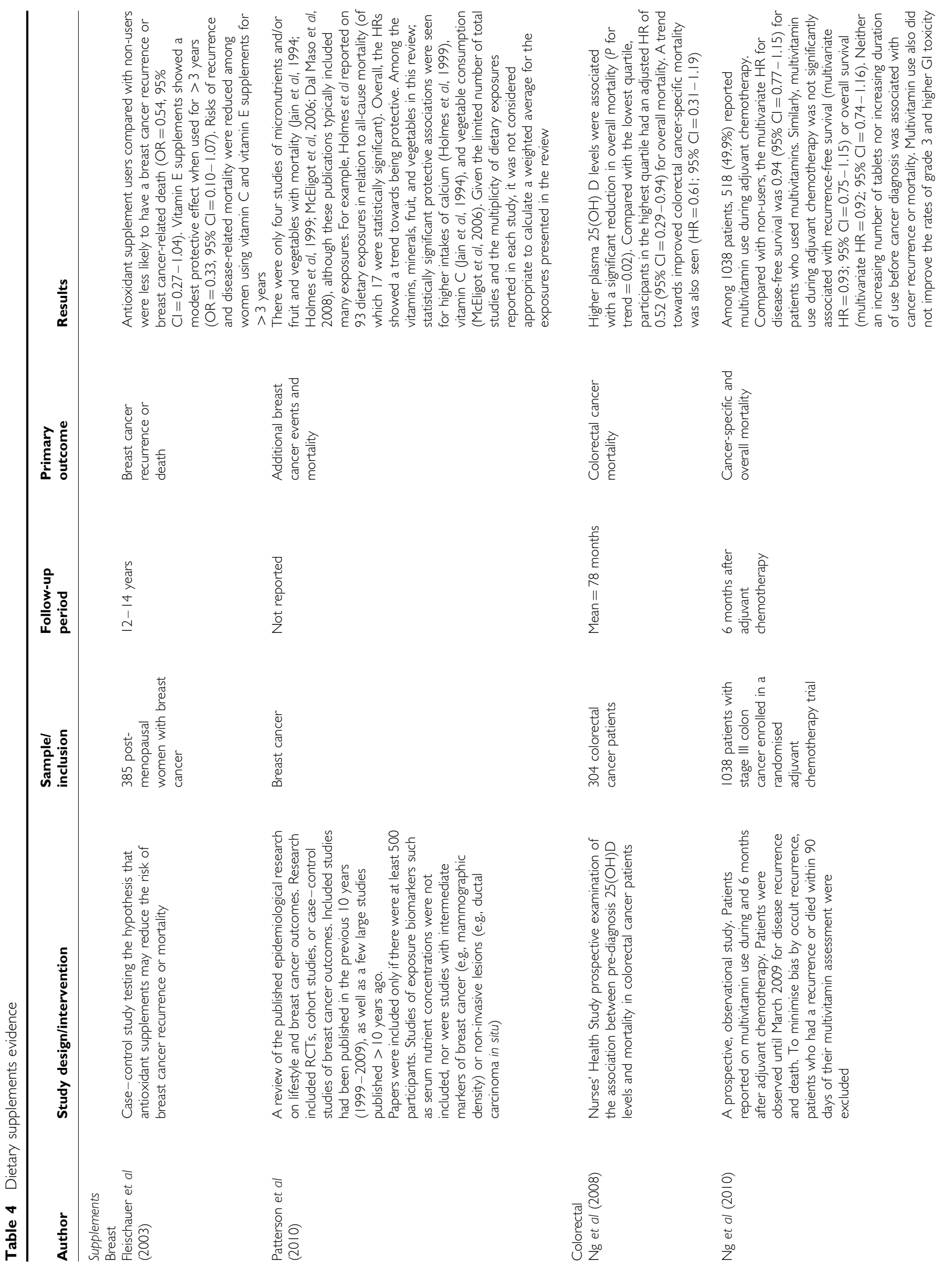




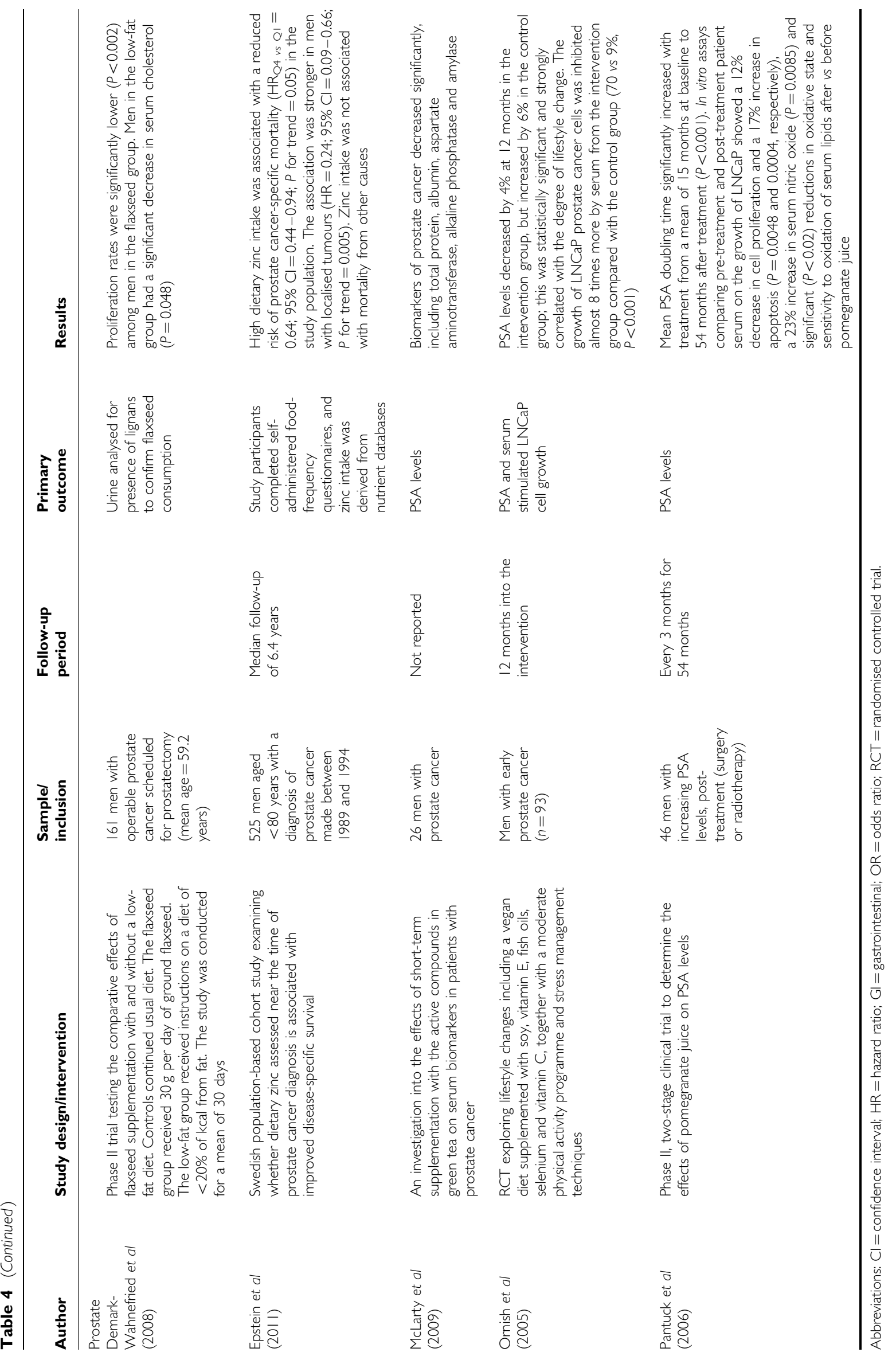




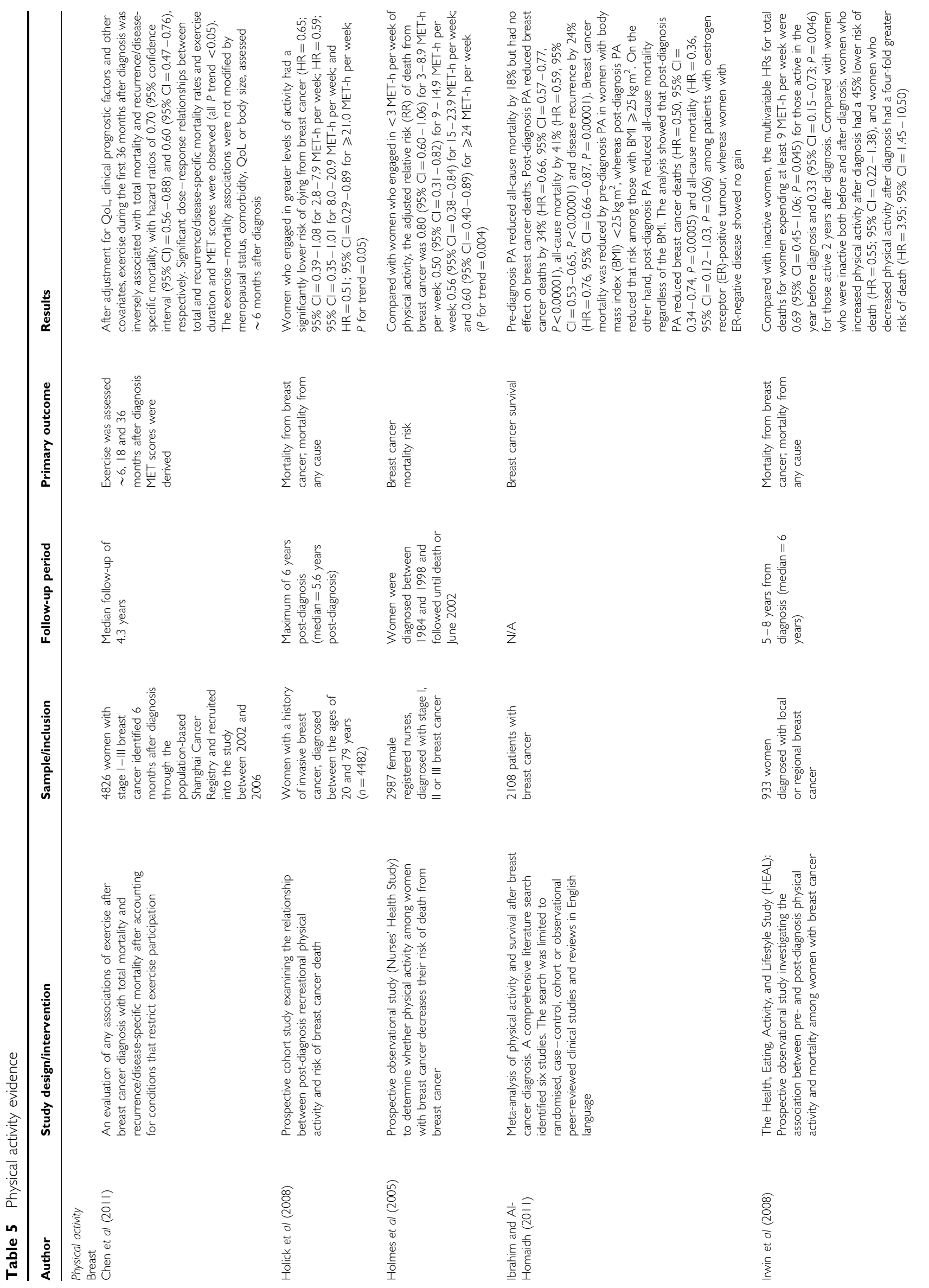




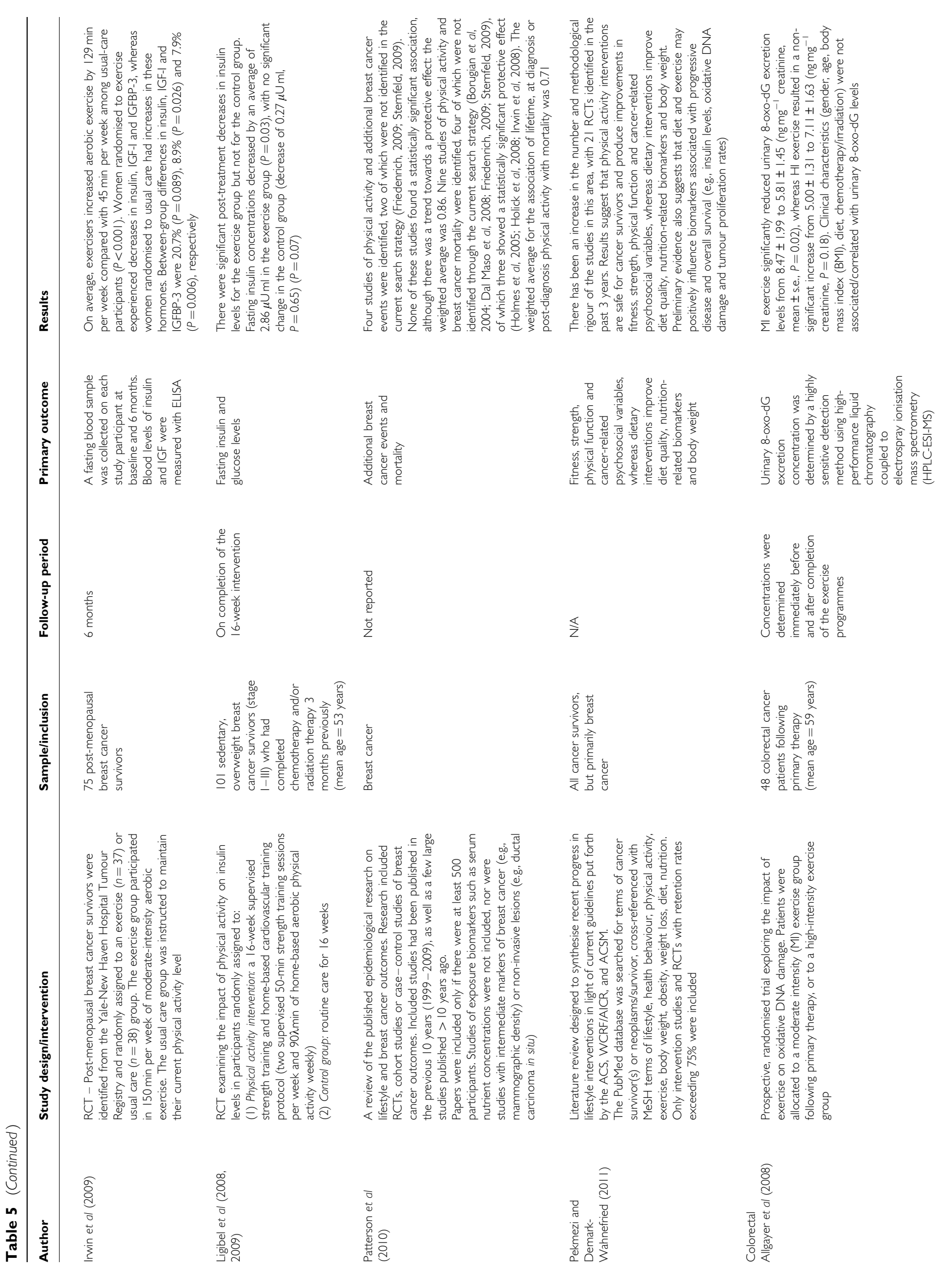




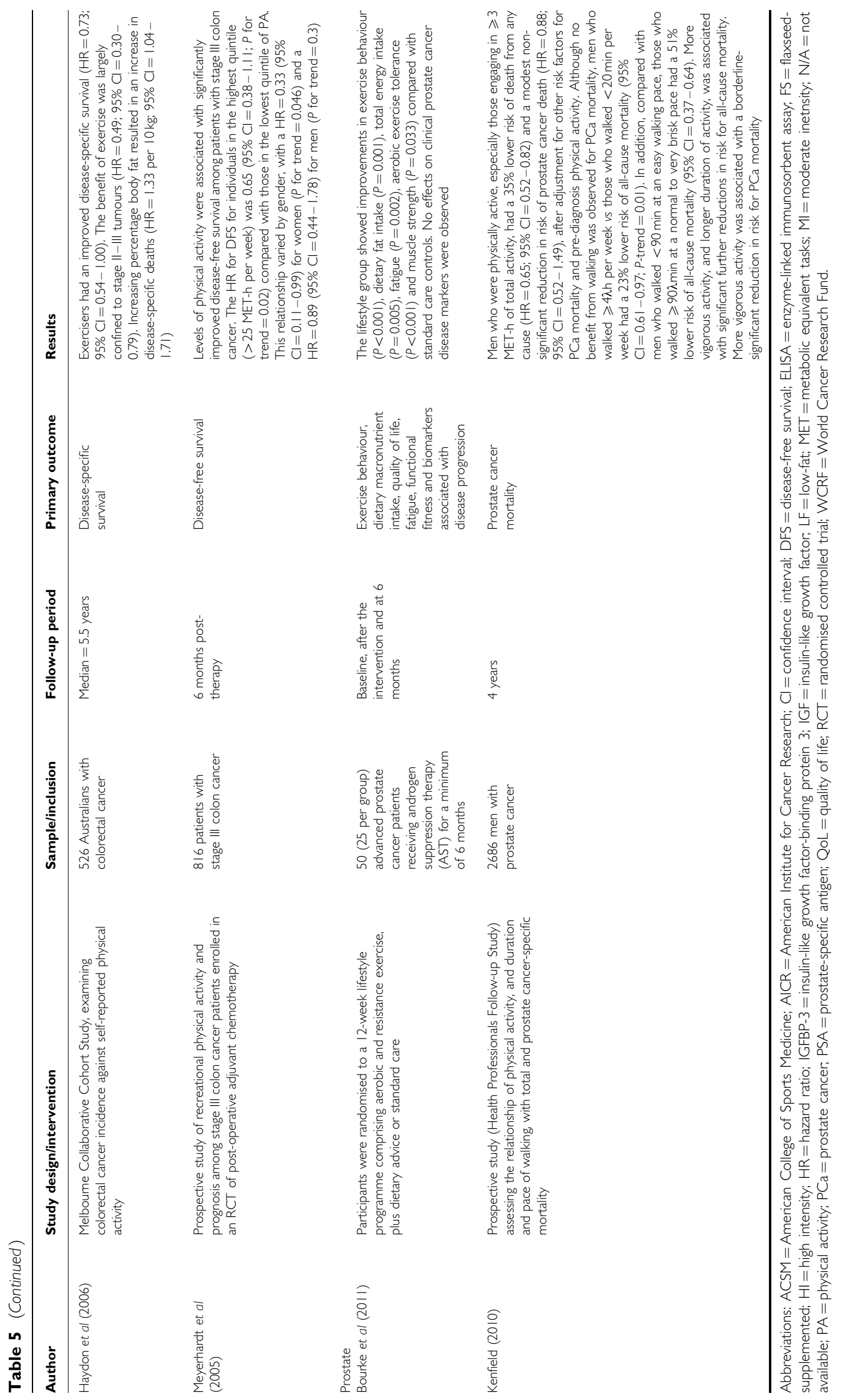




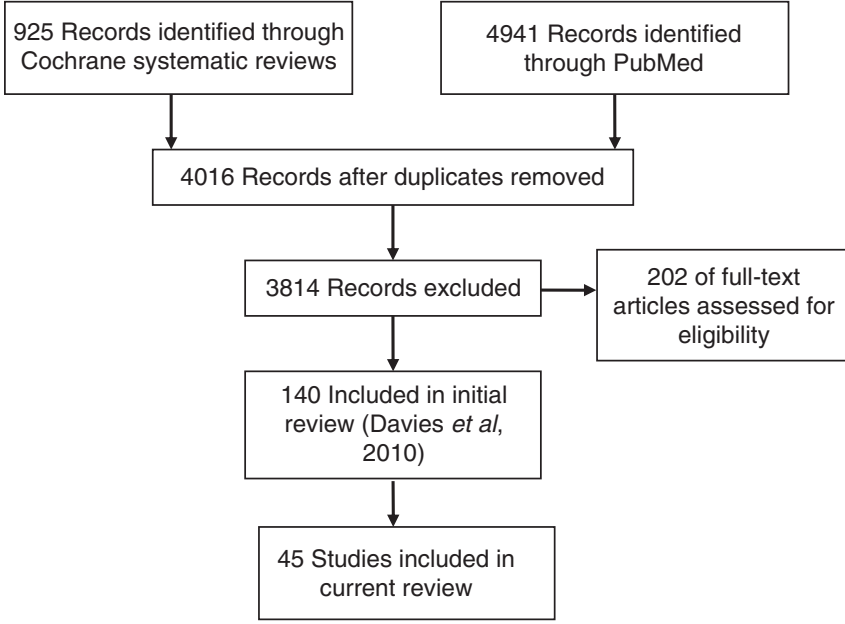

Figure I Flow of information.

There are some notable differences between the WINS and WHEL trials, both of which examined the efficacy of a low-dietaryfat diet on breast cancer prognosis. The main difference was that a better prognosis was found for WINS participants, which could be explained by the lack of weight loss in WHEL participants compared with WINS participants. It is possible that the potential mechanism of benefit produced from low-fat, high-fruit and vegetable (particularly carotenoids) diets may be through changes in weight. Indeed, the majority of studies in this review demonstrate an association between weight and cancer-related risks, with higher weight increasing the risks (Hebert et al, 1998; Enger et al, 2004; Lahmann et al, 2005; Patterson et al, 2010). Furthermore, a randomised prospective study by Elkort et al (1981), reviewed by Bekkering et al (2006), designed to evaluate the effects of long-term (12 months) enteral nutritional support in a group of breast cancer patients undergoing chemotherapy, suggests that any significant change in initial body weight, either a gain or a loss, is associated with an increased risk of recurrent disease. The WINS had a much higher rate of attrition by study completion, when compared with WHEL attrition rates. There was a completion rate of $39 \%$ vs $44 \%$ in the intervention and control groups, respectively, after 5 years of the WINS study. In comparison, the completion rate was $83 \%$ for the intervention group $v s 89 \%$ for the control group, after 4 years of the WHEL study. Furthermore, although the level of fat reduction was similar between studies, other dietary behaviours were also targeted in the WHEL trial, including increased vegetable, fruit and fibre intake. This poses implications for determining the primary mechanism of benefit obtained from the intervention.

Expanding on the potential effect of carotenoids on cancer outcomes, higher intake of carotenoid-rich fruit and vegetables has been associated with a significant reduction in oxidative stress biomarkers, in relation to both DNA damage and lipid peroxidation (Giovannelli et al, 2002). Diets low in antioxidants, particularly antioxidant carotenoids provided as vegetables and fruit in the diet, may contribute to increased oxidative stress. However, in a subanalysis of a purposive sample of participants $(n=207)$, Thomson et al (2007) found a significant inverse association between total plasma carotenoid concentrations and oxidative stress; dietary carotenoid levels were not significantly associated with oxidative stress indicators, although dietary lycopene and lutein/zeaxanthin were modestly associated with 8-OHdG levels $(P=0.054$ and 0.088 , respectively). Key findings include a significant inverse association between total plasma carotenoid concentrations and oxidative stress as measured by urinary $8-\mathrm{OhdG}$, and a

moderately significant inverse association with 8 -iso-PGF $2 \alpha$, a protective association that was not shown for dietary carotenoid intake. This is a small sample size, but they were taken from the WHEL RCT.

Additional dietary sources being investigated in terms of breast cancer progress and recurrence include soy and vitamin D. Boyapati et al (2005) found soy intake pre-diagnosis to be unrelated to disease-free breast cancer survival $(\mathrm{HR}=0.99 ; 95 \%$ $\mathrm{CI}=0.73-1.33$ for the highest tertile compared with the lowest tertile) $(n=1459)$. In a prospective cohort study, Goodwin et al (2009) found that women $(n=512)$ with deficient vitamin D levels had a significantly increased risk of distant recurrence $(\mathrm{HR}=1.94$; $95 \% \mathrm{CI}=1.16-3.25)$ and death $(\mathrm{HR}=1.73 ; 95 \% \mathrm{CI}=1.05-2.86)$ than did those with sufficient levels.

The review and meta-analysis by Patterson et al (2010), of epidemiological research on physical activity, diet and adiposity, identified 41 relevant studies with primary outcomes of additional breast cancer events and mortality. A summary of the study focus and meta-analysis findings is as follows:

- For three studies examining carbohydrates (Holmes et al, 1999; Borugian et al, 2004; McEligot et al, 2006), findings were mixed with one report of a statistically significant protective effect (McEligot et al, 2006): the weighted average was 0.74 .

- For five studies on dietary fat (Jain et al, 1994; Zhang et al, 1995; Borugian et al, 2004; McEligot et al, 2006; Dal Maso et al, 2008), four HRs showed a trend towards increased risk, although only one had a statistically significant finding (McEligot et al, 2006): the weighted HR was 1.53 .

- For three studies of dietary fibre, there was a trend towards being protective (Holmes et al, 1999; Borugian et al, 2004; McEligot et al, 2006), with two being statistically significant (Holmes et al, 1999; McEligot et al, 2006): the weighted average was 0.63 .

- Of four studies that reported on protein (Holmes et al, 1999; Borugian et al, 2004; McEligot et al, 2006; Dal Maso et al, 2008), two found a statistically significantly protective association (Holmes et al, 1999; Borugian et al, 2004): the weighted average was 0.72 .

- A prudent dietary pattern (high intakes of fruits, vegetables, whole grains, legumes, poultry, and fish) appeared protective (Kroenke et al, 2005; Kwan et al, 2009), with one statistically significant finding (Kwan et al, 2009). In contrast, the Western dietary pattern (high intakes of refined grains, processed and red meats, desserts, high-fat dairy products, and fries) was associated with a non-significant increase in risk (Kroenke et al, 2005; Kwan et al, 2009).

An important strength of the review by Patterson et al (2010) is that data are reported separately for observational studies $v s$ RCTs. Furthermore, studies are included only if they comprise at least 500 participants. Unfortunately, however, they did not report on studies of exposure markers such as serum nutrient concentrations, which can offer insights into the protective benefit of dietary interventions.

The protective effect of fibre found in the systematic review by Patterson et al (2010) was partially supported by a more recent observational study conducted by Belle et al (2011). In this study, the HEAL (Health, Eating, Activity, and Lifestyle) study, an inverse association was found between fibre intake and breast cancer mortality $(n=688)$. Multivariate-adjusted hazard rate ratios (HRRs) comparing high with low intake were $0.53(95 \%$ $\mathrm{CI}=0.23-1.23)$ and $0.75(95 \% \mathrm{CI}=0.43-1.31)$. A threshold effect was observed, whereby no additional benefit was observed for intakes of $\geqslant 9 \mathrm{~g}$ per day. Fibre intake was inversely associated with breast cancer-specific mortality $(\mathrm{HRR}=0.68 ; 95 \% \mathrm{CI}=0.27-1.70)$ and risk of non-fatal recurrence or second occurrence $(\mathrm{HRR}=$ $0.68 ; 95 \% \mathrm{CI}=0.27-1.70)$, but results were not statistically 
significant. High-fibre diets are generally low in fat, which might be one mechanism of benefit. Another possible mechanism of benefit is that fibre-rich diets have been shown to improve insulin sensitivity, with an associated reduction in circulating oestrogen levels, which might suppress breast cancer growth.

Colorectal cancer Bekkering et al (2006) reported on six highfibre diet interventions that showed little effect on the risk of recurrence. Data from one trial in patients with colorectal preinvasive lesions evaluated the effect of calcium $v s$ placebo on the risk of developing cancer and found little evidence of effect. On combining the data from two $\beta$-carotene trials, four multivitamin trials, and one trial containing a multivitamin group and an $\mathrm{N}$-acetylcysteine (found in high-protein foods) group, there was weak evidence of a reduction in the risk of colorectal polyps (abnormal growth of tissues in the colon) with these. Two calcium interventions showed some evidence of a reduced risk of recurrence.

One prospective observational study was identified in the current review. Meyerhardt et al (2007) examined dietary patterns in patients $(n=1009)$ who had been successfully treated for stage III colorectal cancer, following them for a median of 5.3 years. During this time, there was a significant difference between those who had followed a 'prudent' diet (i.e., high intake of fruit, vegetables, poultry, and fish) and those who had followed a 'Western' diet (i.e., high intake of meat, fat, refined grains, sweets, and desserts). A higher intake of a Western dietary pattern was associated with a significantly worse disease-free survival (DFS). Compared with patients in the lowest quintile of the Western dietary pattern, those in the highest quintile experienced an adjusted HR (AHR) for DFS of 3.25 (95\% CI = 2.04-5.19; $P$ for trend $<0.001)$. The Western dietary pattern was associated with a similar detriment in recurrence-free survival $(\mathrm{AHR}=2.85$; $95 \% \mathrm{CI}=1.75-4.63)$ and $\mathrm{OS}(\mathrm{AHR}=2.32 ; 95 \% \mathrm{CI}=1.36-3.96)$, comparing the highest with the lowest quintiles (both with $P$ for trend $<0.001)$. The reduction in DFS with a Western dietary pattern was not significantly modified by sex, age, nodal stage, body mass index, physical activity level, baseline performance status or treatment group. In contrast, the prudent dietary pattern was not significantly associated with cancer recurrence or mortality.

Prostate cancer Bekkering et al (2006) did not provide any evidence for the role of diet in prostate cancer survival.

A recent prospective, randomised intervention by Aronson et al (2010) examined a 4-week low-fat diet compared with a Western diet in newly diagnosed prostate cancer patients $(n=18)$. Findings suggest that a low-fat diet might inhibit the growth rate of hormonally responsive prostate cancer cells. A more recent exploration of changes in 50 plasma cytokines and angiogenic factors (CAFs) in prostate cancer patients enrolled in this RCT suggests that a low-fat diet without flaxseed may reduce levels of specific inflammatory CAFs and suggests that the NF- $\kappa \mathrm{B}$ pathway may be a mediator of these changes (Heymach et al, 2011).

Parsons et al (2008) used telephone counselling to promote increased consumption of fruit and vegetables over a 6-month study period $(n=43)$. Although men in the intervention group consumed significantly more vegetables and had significantly higher serum levels of carotenoids, as confirmed by increases in serum carotenoids, the intervention produced a non-significant increase in PSA; there was a non-significant change in mean PSA levels, of +2.28 in the intervention group $v s-0.06$ in the control group $(P=0.29)$. This was a small-scale study reliant on self-report for broadly defined dietary changes.

Richman et al (2010) conducted a prospective study of the association between post-diagnostic consumption of processed and unprocessed red meat, fish, poultry and eggs and the risk of prostate cancer recurrence or progression $(n=1294)$. They found that intakes of processed and unprocessed red meat, fish, total poultry and skinless poultry were not associated with recurrence or progression. Greater consumption of eggs and poultry with skin was associated with twofold increases in risk in a comparison of extreme quantiles: eggs $(\mathrm{HR}=2.02 ; 95 \% \mathrm{CI}=1.10-3.72 ; P$ for trend $=0.05)$ and poultry with skin $(\mathrm{HR}=2.26 ; 95 \% \mathrm{CI}=1.36$ 3.76; $P$ for trend $=0.003$ ). The overall findings suggest that the consumption of processed or unprocessed red meat, fish or skinless poultry post diagnosis may not be associated with prostate cancer recurrence or progression, whereas post-diagnosis consumption of eggs and poultry with the skin may increase the risk.

A recent review conducted by Hori et al (2011) highlights that there is some evidence suggesting that green tea, isoflavone, lycopene, cruciferous vegetable and omega- 3 polyunsaturated fatty acid intake is beneficial in the prevention and/or progression of prostate cancer. They also found evidence to suggest that a high total fat, meat (especially well cooked) and multivitamin intake may be associated with an increased risk of developing prostate cancer, but more research is required to establish its effect on progression. In Hori et al's (2011) review, RCTs were favoured over observational studies, indicating quality data synthesis.

\section{Dietary supplements}

The systematic review on the effects of nutritional and physical activity interventions and cancer survival by Bekkering et al (2006) reports there to be little evidence that a dietary supplement taken separately or in combination with a healthy diet or physical activity is associated with a reduction in all-cause mortality. Of nine trials that included an antioxidant supplement, no evidence was found for an association between this intervention and allcause mortality, compared with placebo or usual treatment. There was no evidence of an effect of retinol (vitamin A) on all-cause mortality, cancer mortality or DFS compared with the usual treatment.

Table 4 presents evidence obtained on dietary supplements for breast, colorectal and prostate cancers.

Breast cancer In a case-control study testing whether antioxidant supplements reduce breast cancer recurrence or mortality $(n=385)$, Fleischauer et al (2003) found that antioxidant supplement users compared with non-users were less likely to have a breast cancer recurrence or breast cancer-related mortality $(\mathrm{OR}=0.54,95 \% \mathrm{CI}=0.27-1.04)$. Vitamin $\mathrm{E}$ supplements showed a modest protective effect when used for $>3$ years $(\mathrm{OR}=0.33,95 \%$ $\mathrm{CI}=0.10-1.07)$. Furthermore, risks of recurrence and diseaserelated mortality were reduced among women using vitamin $\mathrm{C}$ and E supplements for $>3$ years. However, these findings are all statistically non-significant, with widespread CI levels, and there is no information regarding which factors would indicate the dietary patterns of these two groups and which may confound the findings of the study.

In a systematic review of published epidemiological studies on lifestyle and breast cancer mortality, Patterson et al (2010) found that in four studies (Jain et al, 1994; Holmes et al, 1999; McEligot et al, 2006; Dal Maso et al, 2008), there was an overall trend towards being protective. Statistically significant protective associations were found for higher intakes of calcium (Holmes et al, 1999), vitamin C (Jain et al, 1994) and vegetables (McEligot et $a l, 2006)$. A notable weakness in the review by Patterson et al (2010) is that included studies were limited to those vitamins and minerals that can be obtained through self-report and therefore physiological markers of supplement intake were not evaluated. Furthermore, given the heterogeneity across studies, it is impossible to provide conclusive recommendations for these supplements. 
Colorectal cancer The WCRF report provides evidence that serum albumin, alkaline phosphatase, lactic dehydrogenase levels and percentage targeted caloric intake are significant independent predictors of survival duration (Evans et al, 1987). On the other hand, there was no evidence that either $\beta$-carotene or vitamins $\mathrm{C}$ and $\mathrm{E}$ reduced the incidence of colorectal adenomas (Greenberg et al, 1994). Vitamin $C$ therapy also showed no advantage over placebo therapy with regard to either the interval between the beginning of treatment and disease progression or patient survival (Moertel et al, 1985). The evidence within the current review adds very little to these findings.

$\mathrm{Ng}$ et al (2008) examined pre-diagnosis levels of vitamin D in a cohort of participants with colorectal cancer $(n=304)$ from the Nurses' Health Study, which demonstrated that higher plasma (blood) vitamin D levels were associated with a significant reduction in overall mortality. The focus of the study was on pre-diagnosis vitamin $\mathrm{D}$. The findings suggested a $48 \%$ reduction between the highest and lowest quartiles of plasma 25(OH)D. However, for colorectal cancer mortality, the multivariate HR was attenuated to a statistically non-significant reduction of $39 \%$ between the extreme quartiles. Ulrich and Holmes (2008) pointed out that this study needs to be followed up with a larger cohort and an RCT to determine whether colorectal cancer survivors should be advised to take vitamin $\mathrm{D}$ supplements.

$\mathrm{Ng}$ et al (2010) also conducted a prospective, observational study exploring the influence of multivitamin supplements on cancer recurrence and death after a curative resection of colorectal cancer $(n=1038)$. Compared with non-users, the multivariate HR for DFS was $0.94(95 \% \mathrm{CI}=0.77-1.15)$ for patients who used multivitamins. Similarly, multivitamin use during adjuvant chemotherapy was not significantly associated with recurrencefree survival (multivariate $\mathrm{HR}=0.93 ; 95 \% \mathrm{CI}=0.75-1.15$ ) or $\mathrm{OS}$ (multivariate $\mathrm{HR}=0.92 ; 95 \% \mathrm{CI}=0.74-1.16$ ). This is believed to be the first study to examine the impact of multivitamin use on survival in colorectal cancer patients. Furthermore, the sample size was reasonably large and the fact that participants were from a clinical trial reduced the impact of heterogeneity by disease stage. However, this study did rely on self-reports of multivitamin use, which poses issues around accuracy and reliability, as does the fact that multivitamin users are also likely to partake in other health behaviours that might impact the outcomes, including 'healthy' dietary patterns.

Prostate cancer Ornish et al (2005) used an RCT to investigate the effects of intensive dietary and lifestyle changes on PSA levels of men with early prostate cancer $(n=93)$. The lifestyle changes in this study included a low-fat, vegan diet supplemented with soy, vitamin $\mathrm{E}$, fish oils, selenium and vitamin $\mathrm{C}$, together with a moderate physical activity programme, and stress management techniques such as yoga. It was found that PSA levels decreased by $4 \%$ at 12 months in the intervention group, but increased by $6 \%$ in the control group. Furthermore, the growth of LNCaP prostate cancer cells was inhibited almost 8 times more by serum in the intervention group compared with the control group $(70 \%$ vs $9 \%, P<0.001)$. Both changes in serum PSA and LNCaP cell growth were significantly associated with the degree of change in diet and lifestyle. However, the intervention also included a physical activity element, leading to lack of clarity as to whether it was the dietary changes, physical activity or a combination of both that may affect PSA levels. In addition, the intensity of this intervention and associated behavioural changes might not be easily translated into normal healthy eating patterns (White et al, 2009).

Bettuzzi et al (2006), in a year-long clinical trial, have demonstrated that daily consumption of green tea can produce a 10 -fold decrease in the rate at which prostate intraepithelial neoplasia (a pre-cancerous condition) progresses to prostate cancer. Support for these findings is offered by researchers of the Louisiana State University, who conducted an uncontrolled, open-label, single-arm phase II clinical trial testing the efficacy of Polyphenon E, which contains the polyphenol antioxidants found in green tea (McLarty et al, 2009). On taking 4 capsules of Polyphenon E daily (equivalent to 12 cups of green tea) for an average of 34.5 days leading up to radical prostatectomy, participants $(n=26)$ experienced significant reductions in the biomarkers used to monitor the likelihood of metastasis. Some patients demonstrated reductions $>30 \%$. Future research in this area would require a controlled trial to avoid the bias of an observational study with small sample size.

Salicylate intake has been implicated in the aetiology of prostate cancer, but Thomas et al (2009) have evaluated their influence on established cancer progression. In a randomised, double-blind, phase II study involving men $(n=110)$ with progressive prostate cancer who were counselled to eat less saturated fat and processed food, more fruit, vegetables and legumes, engage in physical activity more regularly and to stop smoking, men were then randomised to take sodium salicylate alone or combined with vitamin $\mathrm{C}$, copper and manganese gluconates daily. Although there was no difference in outcome between those who received sodium salicylate alone or combined, the intervention as a whole (i.e., dietary counselling) slowed or stopped the rate of PSA progression in 40 patients $(36.4 \%)$ for $>1$ year, and a further 10 patients were stabilised for 10 months. These data suggest that changes in dietary components towards a more healthy diet may potentially delay PSA progression, although further study on the effects of micronutrients is required.

The potential benefits of pomegranate juice on prostate cancer outcomes appear frequently in the media, and strong evidence of its efficacy can be found within the academic literature. In a phase II, open-label, single-arm clinical trial, men $(n=46)$ with recurrent prostate cancer who had increasing PSA after surgery or radiotherapy were treated daily with $8 \mathrm{oz}(227 \mathrm{~g})$ equivalent of pomegranate juice (Pantuck et al, 2006). Mean PSA doubling time significantly increased with treatment from 15 to 54 months, demonstrating a good indication of a relationship between the consumption of pomegranate juice and prostate health.

In a phase II trial testing the comparative effects of flaxseed supplementation ( $30 \mathrm{~g}$ per day) with and without a low-fat diet against controls who continued their usual diet, dietary fat restriction was not associated as strongly with prostate cancer cell growth as flaxseed supplementation $(n=161)$ (Demark-Wahnefried et al, 2008).

More recently, Epstein et al (2011) conducted a Swedish population-based cohort study examining whether dietary zinc assessed near the time of prostate cancer diagnosis was associated with improved disease-specific survival $(n=525)$. High dietary zinc intake was associated with a reduced risk of prostate cancerspecific mortality $(P=0.05)$. The association was stronger in men with localised tumours $(\mathrm{HR}=0.24 ; 95 \% \mathrm{CI}=0.09-0.66 ; P$ for trend $=0.005$ ).

\section{Physical activity}

Although rest is important in recovery from cancer treatment, there has traditionally been an overemphasis on conserving energy. An implication of this is that insufficient physical activity over time leads to loss of physical conditioning and muscular strength, which makes it difficult to perform even basic activities of daily living (Ness et al, 2006). There is substantial evidence that physical activity can help relieve treatment-related symptoms, such as fatigue (Stevinson and Courneya, 2009). However, there are now also promising data suggesting that physical activity after diagnosis is associated with improved survival. The precise mechanisms through which physical activity may influence cancer recurrence and mortality have not been established, but areas of ongoing research include the role of adiposity, metabolic and sex 
hormones, growth factors, immunological processes and chronic inflammation (Pekmezi and Demark-Wahnefried, 2011).

Guidelines have been published by the American College of Sports Medicine for patients with cancer (ACSM, 2010), which are compatible with the American Cancer Society's recommendation of 30-60 min of moderate-to-vigorous intensity physical activity at least 5 days per week for survivors who are otherwise healthy. There are currently no formal physical activity guidelines for cancer survivors in the United Kingdom. However, a recent expert statement by the British Association of Sports and Exercise Sciences on exercise and cancer survivorship (Campbell et al, 2011, Table 1) also recommends that unless otherwise advised, cancer survivors should follow the health-related physical activity guidelines produced in 2011 for the general UK population (Table 1). All cancer survivors, including those with existing disease or those who are undergoing difficult treatments, should be encouraged, as a minimum, to avoid being sedentary (Campbell et al, 2011).

Table 5 presents evidence on physical activity for breast, colorectal and prostate cancers.

Breast cancer The systematic review carried out for the WCRF (Bekkering et al, 2006) on lifestyle and cancer survivorship focused on RCTs. A majority of those RCTs reviewed had quality of life as the primary outcome. None focused on all-cause mortality, whereas one study focused on cancer recurrence (Nieman et al, 1995). Nieman et al (1995) investigated the impact of $60 \mathrm{~min}$ of supervised weight training and aerobic activity 3 times each week for 8 weeks, and found that it did not significantly alter natural killer cell activity relative to the non-exercise control group and would potentially not reduce the risk of recurrence. Although the updated evidence review by Patterson et al (2010) found that there were more studies examining the impact of lifestyle factors on surrogate/biological markers of survival, there were still few studies testing the effects of lifestyle factors (diet and physical activity) on disease progression and OS.

The studies identified in the current review suggest that physical activity may mediate breast cancer recurrence through its effect on hormones, specifically by reducing the levels of oestrogen in the body (Friedenreich et al, 2010) or by shifting the metabolism of oestrogen to favour production of 2-hydroxyestrone $\left(2-\mathrm{OHE}_{1}\right)$ as opposed to $16 \alpha$-hydroxyestrone $\left(16 \alpha=\mathrm{OHE}_{1}\right)$, the former of which has much weaker oestrogenic activity. This shift might also be the result of a change in lean body mass resulting from physical exercise (Campbell et al, 2007).

In a prospective observational study, Irwin et al (2008) compared with inactive women, the multivariable HRs for total mortality for women engaged in at least 9 MET hours (MET-h) per week (e.g., $2-3 \mathrm{~h}$ of brisk walking) were $0.69(95 \%$ $\mathrm{CI}=0.45-1.06 ; P=0.045)$ for those active in the year before diagnosis and $0.33(95 \% \mathrm{CI}=0.15-0.73 ; P=0.046)$ for those active 2 years after diagnosis. Compared with women who were inactive both before and after diagnosis, women who increased their physical activity after diagnosis had a $45 \%$ lower risk of death $(\mathrm{HR}=0.55 ; 95 \% \mathrm{CI}=0.22-1.38)$, and women who decreased their physical activity after diagnosis had a fourfold greater risk of mortality $(\mathrm{HR}=3.95 ; 95 \% \mathrm{CI}=1.45-10.50)$. Consistent with this, a larger prospective observational study of breast cancer survivors ( $n=4482$ ) showed that women who engaged in greater levels of activity had a significantly lower risk of breast cancer mortality $(\mathrm{HR}=0.65 ; 95 \% \mathrm{CI}=0.39-1.08$ for 2.8-7.9 MET-h per week; $\mathrm{HR}=0.59 ; 95 \% \mathrm{CI}=0.35-1.01$ for 8.0-20.9 MET-h per week; and $\mathrm{HR}=0.51 ; 95 \% \mathrm{CI}=0.29-0.89$ for $\geqslant 21.0$ MET-h per week; $P<0.05$ ) (Holick et al, 2008). Overall, women who were physically active for $>2.8$ MET-h per week (e.g., walking at an average pace of $2-2.9 \mathrm{mph}$ for $1 \mathrm{~h}$ ) had a significantly lower risk of mortality from breast cancer (35-49\% reduction) (Holick et al, 2008). The reduced risk of mortality was limited to total or moderate-intensity physical activity; no benefit was noted for vigorous-intensity activity.

Ligibel et al (2008) conducted an RCT to test the impact of weight training on insulin levels in overweight, sedentary stage IIII breast cancer survivors $(n=101)$. The rationale for this study is that the beneficial effects of physical activity on cancer survival might be mediated through beneficial changes in metabolic hormones (insulin), insulin-like growth factor (IGF)-1 and its binding protein IGFBP-3 (Pekmezi and Demark-Wahnefried, 2011). Women were randomly assigned to one of two conditions: a 16-week supervised strength training and home-based cardiovascular training protocol (two supervised 50-min strength training sessions per week and $90 \mathrm{~min}$ of home-based aerobic physical activity weekly) or a control group (routine care for 16 weeks before being offered consultation with a physical activity trainer at the end of the control period). Participation in the intervention was associated with a significant decrease in insulin levels. Therefore, the relationship between physical activity and breast cancer recurrence may be mediated, in part, through changes in insulin levels. Indeed, in an RCT examining the relationship of IGF-I levels with an increased risk of breast cancer mortality, it was found that women randomised to the exercise group (150 min per week of moderate-intensity aerobic exercise) experienced decreases in insulin, IGF-I and IGFBP-3, whereas women randomised to usual care (maintaining current physical activity) had increases in these hormones (Irwin et al, 2009). Between-group differences in insulin, IGF-I and IGFBP-3 were $20.7 \%(P=0.089), 8.9 \%(P=0.026)$ and $7.9 \%(P=0.006)$, respectively. The authors infer that exercise-induced decreases in IGF may mediate the observed association between higher levels of physical activity and improved survival in women diagnosed with breast cancer.

In a systematic review by Patterson et al (2010), leisure-time physical activity (i.e., sports/recreational) was associated with a $30 \%$ decreased risk of mortality. The association between physical activity before and after diagnosis and breast cancer survival has been further examined in a meta-analysis conducted by Ibrahim and Al-Homaidh (2011). This meta-analysis of six studies, although limited in size, demonstrated some promising findings. In particular, it was found that post-diagnosis physical activity reduced breast cancer deaths by $34 \%(\mathrm{HR}=0.66 ; 95 \% \mathrm{CI}=0.57-$ $0.77, P<0.00001)$, all-cause mortality by $41 \%(\mathrm{HR}=0.59 ; 95 \%$ $\mathrm{CI}=0.53-0.65, \quad P<0.00001)$ and disease recurrence by $24 \%$ $(\mathrm{HR}=0.76 ; 95 \% \mathrm{CI}=0.66-0.87 ; P=0.00001)$. The results are an encouraging contribution to the growing evidence for the beneficial effect of physical activity on beast cancer outcomes.

A recent population-based study using the Shanghai Cancer Registry examined the association between physical activity after diagnosis with recurrence and total and cancer-specific mortality in women with stage I-III breast cancer $(n=4826)$ (Chen et al, 2011). The findings indicate that physical activity during the first 36 months after diagnosis was inversely associated with total mortality and recurrence/disease-specific mortality, with HRs of $0.70 \quad(95 \% \quad \mathrm{CI}=0.56-0.88)$ and $0.60 \quad(95 \% \quad \mathrm{CI}=0.47-0.76)$, respectively. Significant dose-response relationships between total and recurrence/disease-specific mortality rates and exercise duration and MET scores were also observed $(P<0.05)$. Associations between physical activity and mortality were not modified by menopausal status, comorbidity or body size, which was assessed $\sim 6$ months after diagnosis.

Colorectal cancer The observational study by Haydon et al (2006) demonstrated that self-reported leisure-time physical activity (at least once per week) before diagnosis was associated with improved cancer-specific survival in colorectal cancer survivors $(n=526)$. Those who reported regular physical activity (at least once per week) before diagnosis had improved cancer-specific survival (73\% 5-year survival) compared with those not reporting 
regular physical activity (61\% 5-year survival). However, this study does suffer from the methodological limitations of an observational design. Another prospective study of stage III colorectal cancer survivors $(n=816)$, over a 3 -year period after surgery and chemotherapy, showed increases in DFS and OS with increasing volumes of physical activity $(P<0.05)$ (Meyerhardt et al, 2005).

One mechanism by which physical activity may exert its influence on colorectal cancer prognosis could be through the modulation of oxidative DNA damage, which is implicated in carcinogenesis and may be important for cancer progression and relapse. In a hospitalbased exercise programme comparing moderate $v s$ high-intensity exercise over 2 weeks for $30-40 \mathrm{~min}$ per day, colorectal cancer patients $(n=48)$ showed reduced oxidative DNA damage as measured by pre- and post-intervention urinary 8-oxo-dG excretion concentrations $\left(8.47 \pm 1.99\right.$ to $5.91 \pm 1.45 \mathrm{ng} \mathrm{mg}^{-1}$ creatinine, $P=0.02$ ) (Allgayer et al, 2008). On the other hand, high-intensity exercise was associated with increased DNA damage $(5.00+1.31$ to $7.11+1.63 \mathrm{ng} \mathrm{mg}^{-1}$ creatinine, $P=0.18$ ) (Allgayer et al, 2008). This suggests that the intensity of physical activity might have an important role in colorectal cancer progression, raising the need for RCTs to further examine this.

Another potential mechanism of benefit is reduced weight in colorectal cancer survivors who are physically active. Drawing on seven RCTs, Sinicrope et al (2010) provide evidence for BMI being significantly associated with both DFS and OS. There is also some evidence of gender differences; being overweight was associated with improved OS in men, whereas being underweight was associated with significantly worse OS in women.

Prostate cancer The underlying mechanisms for the direct anticancer effect of lifestyle has been indicated in a study that took serum (blood plasma) from men undergoing a low-fat, high-fibre diet and physical activity intervention, and added it to androgendependent LNCaP cells in the laboratory (Soliman et al, 2009). There was decreased growth and increased apoptosis (cell death), associated with a reduction in serum IGF-1. These findings suggest that diet and physical activity interventions might slow prostate cancer progression and aid in its treatment during the early stages of development.

In a prospective study, Kenfield (2010) examined the data of 2686 men from the Health Professionals Follow-Up Study and found that men who engaged in $>3$ MET-h of weekly physical activity after diagnosis reduced their risk of death by $35 \%$ compared with men who engaged in fewer than 3 MET-h of weekly activity. Furthermore, men who walked $90 \mathrm{~min}$ per week at a normal-to-brisk pace had a 51\% lower risk of death due to any cause compared with men who walked $\leqslant 90 \mathrm{~min}$ at an easy pace. To reduce their risk of cancer-specific death, men had to engage in vigorous activity, such as jogging (6 MET-h). A sensitivity analysis in which updating of activity was stopped before a diagnosis of metastasis showed that the results remained unchanged. Self-report of exercise is a limiting factor in the design of this study. However, the findings are indicative of a protective gradient benefit of physical activity intensity levels in terms of prostate cancer/and overall mortality, which is in contrast with the breast cancer study conducted by Holick et al (2008), which found no increased benefit of partaking in vigorous activity.

In a more recent RCT, Bourke et al (2011) examined the association between exercise and prostate cancer outcomes $(n=50)$. Patients receiving androgen suppression therapy for a minimum of 6 months were randomised to a 12-week lifestyle programme comprising aerobic and resistance exercise, plus dietary advice $(n=25)$ or standard care $(n=25)$. Although the lifestyle group showed improvements in exercise behaviour $(P<0.001)$, dietary fat intake $(P=0.001)$, total energy intake $(P=0.005)$, fatigue $(P=0.002)$, aerobic exercise tolerance $(P<0.001)$ and muscle strength $(P=0.033)$ compared with the standard-care control group, no effects on clinical prostate cancer disease markers were observed. This was a very small study that cannot be generalised to other prostate cancer survivors. Furthermore, its primary aim was to examine outcomes such as QoL and fatigue, and therefore the design lacked a focus on measuring markers of disease progression. A larger study is required, with refined outcomes.

\section{DISCUSSION}

The purpose of this review was to update the literature review undertaken in 2010 for the NCSI (Davies et al, 2010), which covered evidence on lifestyle and cancer survivorship between 2006 and 2010, and to include observational studies that were in the main excluded from the WCRF survivorship systematic review (Bekkering et al, 2006). By updating the 2010 review and refining the focus to the lifestyle factors of diet, physical activity and supplements in relation to breast, prostate and colorectal cancer survivorship, further insight has been gained into how these factors might affect cancer prognosis.

The early contradictory findings from the large-scale WINS and WHEL trials in the 1990s and their subsequent secondary analysis studies (Khaodhiar et al, 2003; Chlebowski et al, 2006, 2008; Pierce et al, 2007; Thomson et al, 2007; Dwyer et al, 2008; Gold et al, 2009; Caan et al, 2011) established a strong focus on the role of fat reduction and significant changes in diet (including fat reduction) as important factors for breast cancer prognosis. This was especially so for post-menopausal breast cancer survivors. A recent review and meta-analysis by Patterson et al (2010) of the findings of the WINS and WHEL trials and the secondary analysis studies does indicate that, even after accounting for study weaknesses, dietary intervention without weight loss or physical activity is not sufficient to improve breast cancer prognosis. A study by Ewertz et al (2011) indicates that obesity is an independent prognostic risk factor for the development of distant metastases and mortality after breast cancer diagnosis (Sinicrope and Dannenberg, 2011). Although at this point strong and definitive evidence that weight loss in obese patients $\left(\mathrm{BMI}>30 \mathrm{~kg} \mathrm{~m}^{-2}\right)$ with breast cancer will improve cancer outcomes is lacking, weight reduction and increased physical activity may well achieve the objective and should also have a positive effect on comorbid conditions such as diabetes and cardiovascular disease.

The findings for colorectal and prostate cancer are limited. The 2006 review by Bekkering et al failed to find supporting evidence for a protective effect of dietary fibre on the risk of recurrence for colorectal cancer. The study by Meyerhardt et al (2007) does indicate that a healthy diet may be associated with better outcomes on recurrence and mortality. In particular, a high Western diet (i.e., high intakes of meat, fat, refined grains and dessert) was associated with worse DFS compared with a prudent diet (i.e., high intakes of fruits and vegetables, poultry, and fish). The mechanism of benefit remains unclear as a prudent diet was not independently associated with disease outcomes. Therefore, differences in weight as opposed to diet might be the most plausible explanation for the effect of a Western diet on prognosis.

More recent research focuses on the effect of obesity on the colorectal outcomes of DFS and OS (Sinicrope et al, 2010). The findings of this well-designed study extend the effect of obesity beyond its association with colon cancer risk, to demonstrate that obesity is an independent prognostic variable in colon cancer survivors, which shows differences by gender. Further research will need to study the impact of interventions for obesity on colorectal cancer survivors.

For prostate cancer, an RCT by Ornish et al (2005) found that PSA levels decreased by $4 \%$ at 12 months in prostate cancer patients consuming a vegan diet supplemented with soy, 
vitamin $\mathrm{E}$, fish oils, selenium and vitamin $\mathrm{C}$, together with a moderate physical activity programme and stress management techniques. In contrast, PSA levels increased by $6 \%$ in the control group. Furthermore, the growth of LNCaP prostate cancer cells was inhibited almost 8 times more by serum from the diet group compared with the control group. Both changes in serum PSA and LNCaP cell growth were significantly associated with the degree of change in diet and lifestyle, suggesting that dietary changes can be effective in prostate cancer outcomes.

Clinical trials have also examined the potential benefits of various supplements for prostate cancer outcomes, with weak beneficial effects from pomegranate juice (Pantuck et al, 2006), flaxseed (Demark-Wahnefried et al, 2008), zinc (Epstein et al, 2011) and salicylate intake (Thomas et al, 2009). For pomegranate juice, the mean PSA doubling time significantly increased from 15 to 54 months, indicating a relationship between the consumption of pomegranate juice and prostate health. For flaxseed, the authors report that dietary fat restriction was not associated as strongly with prostate cancer cell growth as flaxseed supplementation (Demark-Wahnefried et al, 2008). On the other hand, high dietary zinc intake was associated with a reduced risk of prostate cancer-specific mortality, the association being stronger in men with localised tumours (Epstein et al, 2011). For salicylate supplementation, although there was no difference in outcome between those who received sodium salicylate and those who did not, the data suggest that changes in dietary components towards a more healthy diet may potentially delay PSA progression (Thomas et al, 2009). These studies offer promising findings, but all comprised a small sample size, ranging from 46 to 525 participants. These findings are synthesised in the review by Hori et al (2011), which also found green tea, isoflavone, lycopene, cruciferous vegetable and omega-3 polyunsaturated fatty acid intake to be beneficial in the prevention and/or progression of prostate cancer.

In evaluating the impact of diet and physical activity on cancer progression and survival, evidence from prospective observational studies suggests that physical activity and diet may be associated with improved cancer progression and recurrence (Khaodhiar et al, 2003; Holmes et al, 2005; Chlebowski et al, 2006, 2008; Pierce et al, 2007; Thomson et al, 2007; Dwyer et al, 2008; Holick et al, 2008; Irwin et al, 2008, 2009; Gold et al, 2009; Goodwin et al, 2009; Belle et al, 2011; Caan et al, 2011; Chen et al, 2011). In particular, the evidence suggests that a low-fat, high-fibre diet might be protective against breast, colorectal and prostate cancer recurrence and progression. There is, however, a paucity of evidence for dietary supplements. Furthermore, any findings from observational studies need to be interpreted with caution because of issues of systematic and random error in self-reported data (Patterson et al, 2010). This is why, as done by Patterson et al (2010), findings from observational studies need to be evaluated against findings from the more rigorous WHEL and WINS RCTs, which produced no sufficient benefit for breast cancer outcomes. It is, however, possible that these RCTs did not target the most relevant dietary components, nor did they adequately distinguish different dietary changes.

Reduced adiposity may be achieved through a low-fat, high-fibre diet and regular physical activity. However, questions remain about the degree of weight loss that may improve the outcomes of cancer survivorship. More rigorous research, particularly RCTs, is required to further distinguish the specific dietary factors and supplements involved in cancer outcomes. On the other hand, evidence from prospective studies suggests that regular physical activity is associated with improved cancer prognosis for breast, prostate and colon cancer survivors (Meyerhardt et al, 2005; Haydon et al, 2006; Allgayer et al, 2008; Irwin et al, 2008, 2009; Ligibel et al, 2008, 2011; Kenfield, 2010; Patterson et al, 2010; Pekmezi and Demark-Wahnefried, 2011) and, indeed, a dose response for increased physical activity and better outcomes (Chen et al, 2011). More vigorous activity, and longer duration of activity, has also been associated with significant further reductions in the risk for all-cause mortality (Kenfield, 2010). RCTs have shown physical activity to cause changes in the biomarkers of cancer risk, whereas observational studies have shed some light on the benefit from physical activity for cancer outcomes (McTiernan, 2008). Overall, the evidence suggests that the physical activity recommendations of the Department of Health (2011) are sufficient for cancer survivors - a total of at least $30 \mathrm{~min}$ a day of moderateintensity physical activity on $\geqslant 5$ days of the week. Even when this might seem too much, survivors can be reminded that the minimum $30 \mathrm{~min}$ per week can be tailored to individual needs and capabilities through graded or progressive physical activity. The evidence for breast cancer further suggests that for survival benefits to be achieved from physical activity, no less than moderate-to-vigorous activity is required (Holick et al, 2008). A recent literature review conducted by Szymlek-Gay et al (2011) suggests that although physical activity levels are low among cancer survivors, most people are interested in increasing their participation. The review also highlights that preferences and adherence to physical activity programmes differ across a range of demographic, medical and behavioural variables, suggesting the importance of tailoring exercise programmes to patient- and disease-specific needs.

Some notable limitations within the current review are that there are less published data for recurrence and cancer events than for all-cause and cancer-specific mortality. Furthermore, some of the studies comprise small sample sizes and few offer evidence for the long-term effects of diet and physical activity on cancer prognosis. Some of the studies that do offer convincing evidence for the beneficial health outcomes associated with diet and physical activity interventions tend to lack external validity. Nevertheless, incomplete scientific evidence can still inform reasonable conclusions that can guide lifestyle choices for cancer survivors (Doyle et al, 2006).

\section{CONCLUSIONS}

The evidence within this review builds upon that in other reviews and suggests that excess weight is an important risk factor for cancer prognosis, which is modifiable through diet and physical activity. However, important questions still remain regarding the degree of weight loss, and levels and intensity of physical activity required to reduce cancer outcomes. As weight gain and a sedentary lifestyle are common after a cancer diagnosis, there is a clear need to target the achievement and maintenance of a healthy weight in cancer survivors. One of the most efficacious ways to achieve this is through dietary changes and the uptake of an active lifestyle, both of which place responsibility and control into the hands of the cancer survivor. The NCSI highlights that people living with or beyond cancer would like to have a more active role in their health care. They want to know how to look after themselves after a cancer diagnosis, including what diet and lifestyle changes they should make, so they can return to a 'normal' life as much as possible (Macmillan Cancer Support, 2008). The challenge, therefore, is in integrating lifestyle support into standardised models of aftercare for cancer survivors.

\section{ACKNOWLEDGEMENTS}

This research was funded by the Department of Health as part of the UK National Cancer Survivorship Initiative, Macmillan Cancer Support. We also extend our thanks to Professor Jessica Corner for her feedback on the review. This article is sponsored by Macmillan Cancer Support. 


\section{REFERENCES}

ACSM (2010) Exercise prescription for other clinical populations. In American College of Sports Medicine's Guidelines for Exercise Testing and Prescription, Thompson WR (ed) 8th edn, pp 228-232. Lippencott, Williams and Wilkins: Baltimore

Allgayer H, Owen RW, Nair J, Spiegelhalder B, Streit J, Reichel C, Bartsch H (2008) Short-term moderate exercise programs reduce oxidative DNA damage as determine by high-performance liquid chromatographyelectrospray ionization-mass spectrometry in patients with colorectal carcinoma following primary treatment. Scand J Gastroenterol 43(8): 971-978

Aronson WJ, Barnard RJ, Freedland SJ, Henning S, Elashoff D, Jardack PM, Cohen P, Heber D, Kobayashi N (2010) Growth inhibitory effect of low fat diet on prostate cancer cells: results of a prospective, randomized dietary intervention trial in men with prostate cancer. J Urol 183(1): $345-350$

Barnett GC, Shah M, Redman K, Easton DF, Ponder BA, Pharoah PD (2008) Risk factors for the incidence of breast cancer: do they affect survival from the disease? J Clin Oncol 26(20): 3310-3316

Bekkering T, Beynon R, Davey Smith G, Davies A, Harbord R, Sterne J, Thomas S, Wood L (2006) A systematic review of RCTs investigating the effect of dietal and physical activity interventions on cancer survival, updated report. World Cancer Research Fund, http://www. dietandcancerreport.org/ (accessed 24 January 2011)

Belle FN, Kampman E, McTiernan A, Bernstein L, Baumgartner K, Baumgartner R, Ambs A, Ballard-Barbash R, Neuhouser ML (2011) Dietary fiber, carbohydrates, glycemic index, and glycemic load in relation to breast cancer prognosis in the HEAL cohort. Cancer Epidemiol Biomarkers Prev 20(5): 890-899

Bettuzzi S, Brausi M, Rizzi F, Castagnetti G, Peracchia G, Corti A (2006) Chemoprevention of human prostate cancer by oral administration of green tea catechins in volunteers with high-grade prostate intraepithelial neoplasia: a preliminary report from a one-year proof-of-principle study. Cancer Res 66: 1234-1240

Borugian MJ, Sheps SB, Kim-Sing C, Patten CV, Potter JD, Dunn B, Gallagher RP, Hislop TG (2004) Insulin, macronutrient intake, and physical activity: are potential indicators of insulin resistance associated with mortality from breast cancer? Cancer Epidemiol Biomarkers Prev 13(7): $1163-1172$

Bourke L, Doll H, Crank H, Daley A, Rosario D, Saxton JM (2011) Lifestyle intervention in men with advanced prostate cancer receiving androgen suppression therapy: a feasibility study. Cancer Epidemiol Biomarkers Prev 20(4): $647-657$

Boyapati SM, Shu XO, Ruan ZX, Dai Q, Cai Q, Gao YT, Zheng W (2005) Soy food intake and breast cancer survival: a follow-up of the Shanghai Breast Cancer Study. Breast Cancer Res Treat 92(1): 11-17

Caan BJ, Natarajan L, Parker B, Gold EB, Thomson C, Newman V, Rock CL, Pu M, Al-Delaimy W, Pierce JP (2011) Soy food consumption and breast cancer prognosis. Cancer Epidemiol Biomarkers Prev 20(5): $854-858$

Campbell A, Stevinson C, Crank H (2011) British Sport and Exercise Scientist, 28, Summer 2011 The BASES Expert Statement on Exercise and Cancer Survivorship

Campbell KL, Westerlind KC, Harber VJ, Bell GJ, Mackey JR, Courneya KS (2007) Effects of aerobic exercise training on estrogen metabolism in premenopausal women: a randomized controlled trial. Cancer Epidemiol Biomarkers Prev 16: 731-773

Chan JM, Gann PH, Giovannucci EL (2005) Role of diet in prostate cancer development and progression. J Clin Oncol 23: 8152-8160

Chen X, Lu W, Zheng W, Gu K, Matthews CE, Chen Z, Zheng Y, Shu XO (2011) Exercise after diagnosis of breast cancer in association with survival. Cancer Prev Res (Phila) 4(9): 1409-1418

Chlebowski RT, Blackburn GL, Hoy MK, Thomson CA, Giuliano AE, McAndrew P, Hudis C, Butler J, Shapiro A, Elashoff RM (2008) Survival analyses from the Women's Intervention Nutrition Study (WINS) evaluating dietary fat reduction and breast cancer outcome. J Clin Oncol 26: (20 May suppl; abstract 522)

Chlebowski RT, Blackburn GL, Thomson CA, Nixon DW, Shapiro A, Hoy MK, Goodman MT, Giuliano AE, Karanja N, McAndrew P, Hudis C, Butler J, Merkel D, Kristal A, Caan B, Michaelson R, Vinciguerra V, Del Prete S, Winkler M, Hall R, Simon M, Winters BL, Elashoff RM (2006) Dietary fat reduction and breast cancer outcome: interim efficacy results from the Women's Intervention Diet Study. J Natl Cancer Inst 98: $1767-1776$
Cho E, Spiegelman D, Hunter DJ, Chen WY, Stampfer MJ, Colditz GA, Willett WC (2003) Premenopausal fat intake and risk of breast cancer. J Natl Cancer Inst 95(14): 1079-1085

Dal Maso L, Zucchetto A, Talamini R, Serraino D, Stocco CF, Vercelli M, Falcini F, Franceschi S (2008) Effect of obesity and other lifestyle factors on mortality in women with breast cancer. Int J Cancer 123(9): $2188-2194$

Davies N, Thomas R, Batehup L (2010) Advising Cancer Survivors About Lifestyle: A Selective Review of the Evidence. Macmillan Cancer Support. http://www.ncsi.org.uk/wp-content/uploads/Lifestyle-Review.pdf

Demark-Wahnefried W, Polascik TJ, George SL, Switzer BR, Madden JF, Ruffin IV MT, Snyder DC, Owzar K, Hars V, Albala DM, Walther PJ, Robertson CN, Moul JW, Dunn BK, Brenner D, Minasian L, Stella P, Vollmer RT (2008) Flaxseed supplementation (not dietary fat restriction) reduces prostate cancer proliferation rates in men presurgery. Cancer Epidemiol Biomarkers Prev 17(12): 3577-3587

Department of Health (2011) UK Physical Activity Guidelines. The Stationary Office: London

Department of Health, Macmillan Cancer Support, NHS Improvement (2010) National Cancer Survivorship Initiative Vision. The Stationary Office: London

Doyle C, Kushi L, Byers T, Courneya K, Demark-Wahnefried W, Grant B, McTiernan A, Rock C, Thompson C, Gansler T, Andrews K (2006) Nutrition and physical activity during and after cancer treatment: an American Cancer Society guide for informed choices. CA: A Journal for Clinicians 56(6): $323-353$

Dwyer J, Peterson J, Winters B, Liu W, Mitchell DC, Atkinson K (2008) Do flavonoid intakes of postmenopausal women with breast cancer vary on very low fat diets? Nutr Cancer 60(4): 450-460

Elkort RJ, Baker FL, Vitale JJ, Cordano A (1981) Long-term nutritional support as an adjunct to chemotherapy for breast cancer. J Parenter Enteral Nutr 5(5): 385-390

Enger SM, Greif JM, Polikoff J, Press M (2004) Body weight correlates with mortality in early-stage breast cancer. Arch Surg 139: 954-958

Epstein MM, Kasperzyk JL, Andrén O, Giovannucci EL, Wolk A, Håkansson $\mathrm{N}$, Andersson SO, Johansson JE, Fall K, Mucci LA (2011) Dietary zinc and prostate cancer survival in a Swedish cohort. Am J Clin Nutr 93(3): $586-593$

Evans WK, Nixon DW, Daly JM, Ellenberg SS, Gardner L, Wolfe E, Shephered FA, Feld R, Gralla R, Fine S (1987) A randomized study of oral nutritional support $v s$ ad lib nutritional intake during chemotherapy for advanced colorectal and non-small-cell lung cancer. J Clin Oncol 5: 113 - 124

Ewertz M, Jensen MB, Gunnarsdóttir KÁ, Højris I, Jakobsen EH, Nielsen D, Stenbygaard LE, Tange UB, Cold S (2011) Effect of obesity on prognosis after early-stage breast cancer. J Clin Oncol 29(1): 25-31

Fleischauer AT, Simonsen N, Arab L (2003) Antioxidant supplements and risk of breast cancer recurrence and breast cancer-related mortality among postmenopausal women. Nutr Cancer 46: 15-22

Friedenreich CM, Gregory J, Kopciuk KA, Mackey JR, Courneya KS (2009) Prospective cohort study of lifetime physical activity and breast cancer survival. Int J Cancer 124(8): 1954-1962

Friedenreich CM, Woolcott CG, McTiernan A, Ballard-Barbash R, Brant RF, Stanczyk FZ, Terry T, Boyd NF, Yaffe MJ, Irwin ML, Jones CA, Yasui Y, Campbell KL, McNeely ML, Karvinen KH, Wang Q, Courneya KS (2010) Alberta physical activity and breast cancer prevention trial: sex hormone changes in a year-long physical activity intervention among postmenopausal women. J Clin Oncol 28: 1458-1466

Giovannelli L, Cozzi A, Guarnieri I, Dolara P, Moroni F (2002) Comet assay as a novel approach for studying DNA damage in focal cerebral ischemia: differential effects of NMDA receptor antagonists and poly(ADPribose) polymerase inhibitors. J Cereb Blood Flow Metab 22: 697-704

Gold EB, Pierce JP, Natarajan L, Stefanick ML, Laughlin GA, Caan BJ, Flatt SW, Emond JA, Saquib N, Madlensky L, Kealey S, Wasserman L, Thomson CA, Rock CL, Parker BA, Karanja N, Jones V, Hajek RA, Pu M, Mortimer JE (2009) Dietary pattern influences breast cancer prognosis in women without hot flashes: the Women's Healthy Eating and Living Trial. J Clin Oncol 27(3): $352-359$

Goodwin PJ, Ennis M, Pritchard KI, Koo J, Hood N (2009) Prognostic effects of 25-hydroxyvitamin D levels in early breast cancer. J Clin Oncol 27: $3757-3763$

Greenberg ER, Baron JA, Tosteson TD, Freeman DH, Beck GJ, Bond JH, Colacchio TA, Coller JA, Frankl HD, Haile RW (1994) A clinical trial of 
antioxidant vitamins to prevent colorectal adenoma. $N$ Engl $J$ Med 331(3): $141-147$

Haydon AM, Macinnis RJ, English DR, Giles GG (2006) The effect of physical activity and body size on survival after diagnosis with colorectal cancer. Gut 55: $62-67$

Hebert JR, Hurley TG, Ma Y (1998) The effect of dietary exposures on recurrence and mortality in early stage breast cancer. Breast Cancer Res Treat 51: $17-28$

Heymach JV, Shackleford TJ, Tran HT, Yoo SY, Do KA, Wergin M, Saintigny P, Vollmer RT, Polascik TJ, Snyder DC, Ruffin MT, Yan S, Dewhirst MW, Kunnamakkara AB, Aggarwal BB, Demark-Wahnefried W (2011) Effect of low-fat diet on plasma levels of NF-\{kappa\}B-regulated inflammatory cytokines and angiogenic factors in men with prostate cancer. Cancer Prev Res (Phila); e-pub ahead of print 15 July 2011

Holick CN, Newcomb PA, Trentham-Dietz A, Titus-Ernstoff L, Bersch AJ, Stampfer MJ, Baron JA, Egan KM, Willett WC (2008) Physical activity and survival after diagnosis of invasive breast cancer. Cancer Epidemiol Biomarkers Prev 17: 379-386

Holmes MD, Chen WY, Feskanich D, Kroenke CH, Colditz GA (2005) Physical activity and survival after breast cancer diagnosis. JAMA 293(20): $2479-2486$

Holmes MD, Hunter DJ, Colditz GA, Stampfer MJ, Hankinson SE, Speizer FE, Rosner B, Willett WC (1999) Association of dietary intake of fat and fatty acids with risk of breast cancer. JAMA 281: 914-920

Hori S, Butler E, McLoughlin J (2011) Prostate cancer and diet: food for thought? BJUI International 107(9): $1348-1359$

Ibrahim EM, Al-Homaidh A (2011) Physical activity and survival after breast cancer diagnosis: meta-analysis of published studies. Med Oncol 28(3): $753-765$

Ingram D (1994) Diet and subsequent survival in women with breast cancer. Br J Cancer 69: $592-595$

Irwin ML, Smith AW, McTiernan A, Ballard-Barbash R, Cronin K, Gilliland FD, Baumgartner RN, Baumgartner KB, Bernstein L (2008) Influence of pre- and postdiagnosis physical activity on mortality in breast cancer survivors: the health, eating, activity, and lifestyle study. J Clin Oncol 26: $3958-3964$

Irwin ML, Varma K, Alvarez-Reeves M, Cadmus L, Wiley A, Chung GG, Dipietro L, Mayne ST, Yu H (2009) Randomized controlled trial of aerobic exercise on insulin and insulin-like growth factors in breast cancer survivors: the Yale Exercise and Survivorship study. Cancer Epidemiol Biomarkers Prev 18(1): 306-313

Jain M, Miller AB, To T (1994) Premorbid diet and the prognosis of women with breast cancer. J Natl Cancer Inst 86(18): 1390-1397

Jones LW, Demark-Wahnefried W (2006) Diet, physical activity, and complementary therapies after primary treatment for cancer. Lancet Oncol 7: 1017-1026

Kenfield SA (2010) Physical activity and mortality in prostate cancer (In regular vigorous physical activity found to have survival benefits for prostate cancer patients AACR frontier in cancer prevention research conference by Tuma R). Oncol Times 32: 29-33

Khaodhiar L, Nixon D, Chlebowski RT, Elashoff R, Blackburn GL, Hoy MK (2003) Insulin resistance in postmenopausal women with breast cancer. Proc Am Cancer Res 44: 6349

Kroenke CH, Fung TT, Hu FB, Holmes MD (2005) Dietary patterns and survival after breast cancer diagnosis. J Clin Oncol 23(36): 9295- 9303

Kwan ML, Weltzien E, Kushi LH, Castillo A, Slattery ML, Caan BJ (2009) Dietary patterns and breast cancer recurrence and survival among women with early-stage breast cancer. J Clin Oncol 27(6): 919-926

Lahmann PH, Schulz M, Hoffmann K, Boeing H, Tjønneland A, Olsen A, Overvad K, Key TJ, Allen NE, Khaw KT, Bingham S, Berglund G, Wirfält E, Berrino F, Krogh V, Trichopoulou A, Lagiou P, Trichopoulos D, Kaaks R, Riboli E (2005) Long-term weight change and breast cancer risk: the European prospective investigation into cancer and nutrition (EPIC). Br J Cancer 93(5): $582-589$

Ligibel JA (2011) Role of adjuvant and posttreatment exercise programs in breast health. JNCCN 9: 251-256

Ligibel JA, Campbell N, Partridge A, Chen WY, Salinardi T, Chen H, Adloff K, Keshaviah A, Winer EP (2008) Impact of a mixed strength and endurance exercise intervention on insulin levels in breast cancer survivors. J Clin Oncol 26(6): 907-912

Ligibel JA, Demark-Wahnefried W, Goodwin PJ (2009) Diet, physical activity, and supplements: guidelines for cancer survivors. ASCO Educational Book 1: $541-547$
Macmillan Cancer Support (2008) Two million reasons. The cancer survivorship agenda: why people need to support people living with or beyond cancer. Macmillan Cancer Support, September 2008, MAC11578

McEligot AJ, Largent J, Ziogas A, Peel D, Anton-Culver H (2006) Dietary fat, fiber, vegetable, and micronutrients are associated with overall survival in postmenopausal women diagnosed with breast cancer. Nutr Cancer 55(2): $132-140$

McLarty J, Bigelow RL, Smith M, Elmajian D, Ankem M, Cardelli JA (2009) Tea polyphenols decrease serum levels of prostate-specific antigen, hepatocyte growth factor, and vascular endothelial growth factor in prostate cancer patients and inhibit production of hepatocyte growth factor and vascular endothelial growth factor in vitro. Cancer Prev Res 2: $673-682$

McTiernan A (2008) Mechanisms linking physical activity with cancer. Nature Reviews Cancer 8: 205-211

Meyerhardt JA, Heseltine D, Niedzwiecki D, Hollis D, Saltz LB, Mayer RJ, Schilsky RL, Fuchs CS (2005) The impact of physical activity on patients with stage III colon cancer: findings from intergroup trial CALGB 89803. Proc Am Soc Clin Oncol 24: 3534

Meyerhardt JA, Niedzwiecki D, Hollis D, Saltz LB, Hu FB, Mayer RJ, Nelson H, Whittom R, Hantel A, Thomas J, Fuchs CS (2007) Association of dietary patterns with cancer recurrence and survival in patients with stage III colon cancer. J Am Med Assoc 298: 754-764

Moertel CG, Fleming TR, Creagan ET, Rubin J, O'Connell MJ, Ames MM (1985) High-dose vitamin C vs placebo in the treatment of patients with advanced cancer who had had no prior chemotherapy. N Engl J Med 312: $137-141$

Moher D, Liberati A, Tetzlaff J, Altman DG, The PRISMA Group (2009) Preferred reporting items for systematic reviews and meta-analyses: The PRISMA Statement. PLoS Med 6(7): e1000097

Ness KK, Wall MM, Oakes JM, Robison LL, Gurney JG (2006) Physical performance limitations and participation restrictions among cancer survivors: a population-based study. Ann Epidemiol 16(3): $197-205$

Ng K, Meyerhardt JA, Chan JA, Niedzwiecki D, Hollis DR, Saltz LB, Mayer RJ, Benson III AB, Schaefer PL, Whittom R, Hantel A, Goldberg RM, Fuchs CS (2010) Multivitamin use is not associated with cancer recurrence or survival in patients with stage III colon cancer: findings from CALGB 89803. J Clin Oncol 28(28): 4354-4363

Ng K, Meyerhardt JA, Wu K, Feskanich D, Hollis BW, Giovannucci EL, Fuchs CS (2008) Circulating 25-hydroxyvitamin d levels and survival in patients with colorectal cancer. J Clin Oncol 26(18): 2984-2991

Nieman DC, Cook VD, Henson DA, Suttles W, Rejeski WJ, Ribisl PM, Fagoaga OR, Nehlsen-Cannarella SL (1995) Moderate exercise training and natural killer cell cytotoxic activity in breast cancer patients. Immunology 16(5): 334-337

Ornish D, Weidner G, Fair WR, Marlin R, Pettengill EB, Raisin CJ, DunnEmke S, Crutchfield L, Jacobs FN, Barnard RJ, Aronson WJ, McCormac P, McKnight DJ, Fein JD, Dnistrian AM, Weinstein J, Ngo TH, Mendell NR, Carroll PR (2005) Intensive lifestyle changes may affect the progression of prostate cancer. J Urol 174: 1065-1070

Pantuck AJ, Leppert JT, Zomorodian N, Aronson W, Hong J, Barnard RJ, Seeram N, Liker H, Wang H, Elashoff R, Heber D, Aviram M, Ignarro L, Belldegrun A (2006) Phase II study of pomegranate juice for men with rising PSA following surgery or RXT for prostate cancer. Clin Cancer Res 12: $4018-4026$

Parsons JK, Newman VA, Mohler JL, Pierce JP, Flatt S, Marshall J (2008) Dietary modification in patients with prostate cancer on active surveillance: a randomized, multicentre feasibility study. $\mathrm{Br} J$ Urol 101: $1227-1231$

Patterson RE, Cadmus LA, Emond JA, Pierce JP (2010) Physical activity, diet, adiposity and female breast cancer prognosis: a review of the epidemiologic literature. Maturitas 66(1): 5-15

Pekmezi DW, Demark-Wahnefried W (2011) Updated evidence in support of diet and exercise interventions in cancer survivors. Acta Oncol 50(2): $167-178$

Pierce JP, Natarajan L, Caan BJ, Parker BA, Greenberg ER, Flatt SW, Rock CL, Kealey S, Al-Delaimy WK, Bardwell WA, Carlson RW, Emond JA, Faerber S, Gold EB, Hajek RA, Hollenbach K, Jones LA, Karanja N, Madlensky L, Marshall J, Newman VA, Ritenbaugh C, Thomson CA, Wasserman L, Stefanick ML (2007) Influence of a diet very high in vegetables, fruit, and fiber and low in fat on prognosis following treatment for breast cancer: the Women's Healthy Eating and Living (WHEL) Randomized Trial. JAMA 298: 289-298 
BJC $\cap$

Richman EL, Stampfer MJ, Paciorek A, Broering JM, Carroll PR, Chan JM (2010) Intakes of meat, fish, poultry, and eggs and risk of prostate cancer progression. Am J Clin Nutr 91(3): 712-721

Schmitz KH, Courneya KS, Matthews C, Demark-Wahnefried W, Galvão DA, Pinto BM, Irwin ML, Wolin KY, Segal RJ, Lucia A, Schneider CM, von Gruenigen VE, Schwartz AL, American College of Sports Medicine (2010) American College of Sports Medicine roundtable on exercise guidelines for cancer survivors. Med Sci Sports Exerc 42(7): 1409-1426. Erratum in: Med Sci Sports Exerc (2011) 43(1):195

Sinicrope FA, Dannenberg AJ (2011) Obesity and breast cancer prognosis: weight of the evidence. J Clin Oncol 29(1): 4-7

Sinicrope FA, Foster NR, Sargent DJ, O'Connell MJ, Rankin C (2010) Obesity is an independent prognostic variable in colon cancer survivors. Clin Cancer Res 16: $1884-1893$

Soliman S, Aronson WJ, Barnard RJ (2009) Analyzing serum-stimulated prostate cancer cell lines after low-fat, high-fiber diet and physical activity intervention. Evidence-Based Complementary and Alternative Medicine Volume 2011 529053: 7

Sonn GA, Aronson W, Litwin MS (2005) Impact of diet on prostate cancer: a review. Prostate Cancer Prostatic Dis 8: 304-310

Sternfeld B, Weltzien E, Quesenberry Jr CP, Castillo AL, Kwan M, Slattery ML, Caan BJ (2009) Physical activity and risk of recurrence and mortality in breast cancer survivors: findings from the LACE study. Cancer Epidemiol Biomarkers Prev 18(1): 87-95

Stevinson C, Courneya KS (2009) Physical activity and cancer. In Integrative Oncology, Abrams DI, Weil A (eds), pp 215-231. Oxford University Press: New York, NY
Role of diet and physical activity in cancer survivorship

NJ Davies et al

Szymlek-Gay EA, Richards R, Egan R (2011) Physical activity among cancer survivors: a literature review. J N Zealand Med Assoc 124(1337): $1-13$

Thomas R, Oakes R, Gordon J, Russell S, Blades M, Williams M (2009) A randomised double-blind phase II study of lifestyle counselling and salicylate compounds in patients with progressive prostate cancer. Diet Food Sci 39(3): 295-305

Thomson CA, Stendell-Hollis NR, Rock CL, Cussler EC, Flatt SW, Pierce JP (2007) Plasma and dietary carotenoids are associated with reduced oxidative stress in women previously treated for breast cancer. Cancer Epidemiol Biomarkers Prevent 16(10): 2008-2015

Ulrich CM, Holmes RS (2008) Shedding light on colorectal cancer prognosis: vitamin d and beyond. J Clin Oncol 26(18): 2937-2939

White SM, McAuley E, Estabrooks PA, Courneya KS (2009) Translating physical activity interventions for breast cancer survivors into practice: an evaluation of randomized controlled trials. Ann Behav Med 37(1): $10-19$

Zhang S, Folsom AR, Sellers TA, Kushi LH, Potter JD (1995) Better breast cancer survival for postmenopausal women who are less overweight and eat less fat. The Iowa Women's Health Study. Cancer 76(2): $275-283$

(c) (1) This work is licensed under the Creative Commons cc. License. To view a copy of this license, visit http://creativecommons. org/licenses/by-nc-sa/3.0/ 